University of Louisville

ThinkIR: The University of Louisville's Institutional Repository

Electronic Theses and Dissertations

$12-2016$

\title{
Examination of the relevance of PI3K and PTEN pathway in Ustilago maydis.
}

Nathaniel Edward Dalton

Follow this and additional works at: https://ir.library.louisville.edu/etd

Part of the Biology Commons, and the Genetics Commons

\section{Recommended Citation}

Dalton, Nathaniel Edward, "Examination of the relevance of PI3K and PTEN pathway in Ustilago maydis." (2016). Electronic Theses and Dissertations. Paper 2566.

https://doi.org/10.18297/etd/2566

This Master's Thesis is brought to you for free and open access by ThinkIR: The University of Louisville's Institutional Repository. It has been accepted for inclusion in Electronic Theses and Dissertations by an authorized administrator of ThinkIR: The University of Louisville's Institutional Repository. This title appears here courtesy of the author, who has retained all other copyrights. For more information, please contact thinkir@louisville.edu. 


\title{
EXAMINATION OF THE RELEVANCE OF PI3K AND PTEN PATHWAY IN USTILAGO MAYDIS
}

\author{
By \\ Nathaniel Edward Dalton \\ B.Sc Informatics, Indiana University Southeast, 2013
}

Thesis

Submitted to the Faculty of the College of Arts and Sciences of the University of Louisville In Partial fulfillment of the Requirements for the Degree of

Master of Science in Biology

Department of Biology

Division of Molecular, Cellular and Developmental Biology

University of Louisville

Louisville, Kentucky

December 2016 

EXAMINATION OF THE RELEVANCE OF PI3K AND PTEN PATHWAY IN USTILAGO MAYDIS

\author{
By \\ Nathaniel Edward Dalton \\ B.Sc Informatics, Indiana University Southeast, 2013
}

A Thesis Approved on

December 1, 2016

By the following Thesis Committee:

Michael H. Perlin, Thesis Director

David J. Schultz

Paula Bates 


\section{DEDICATION}

This thesis is dedicated to my mother, sisters, and grandmother. 


\section{ACKNOWLEDGEMENTS}

It has been a long road and I have grown so much on my academic sojourn. I am grateful to my friends and family that have supported and pushed me when I had all but given up, without their guidance I would have surely failed. I also want to acknowledge and thank every member of the University of Louisville Biology department, especially the members of the GOAT lab. A special thanks to my committee members for their support, guidance, and vast knowledge of which they were eager to share. Lastly, thanks to Dr. Perlin whom, above all, has shown me what it means to be a scholar. 


\title{
ABSTRACT \\ EXAMINATION OF THE RELEVANCE OF PI3K AND PTEN PATHWAY IN USTILAGO MAYDIS
}

\author{
Nathaniel Edward Dalton
}

November 14, 2016

Ustilago maydis is a fungal pathogen that is an obligate parasite on Zea mays (Corn) in order to undergo and complete its sexual life cycle. The cells grow as a haploid form until they meet a compatible partner and undergo a dimorphic switch from a budding yeastlike cell type to a filamentous dikaryon. Infection of the host plant is characterized by leaf chlorosis, anthocyanin content, and formation of large galls that develop on the stem, leaves, cobs, and flowers. Many signaling cascades such as MAPK and PKA are involved in the regulation of the infection lifecycle. The Phosphatidylinosotiol 3 Kinase/ Phosphatase and tensin homolog pathway (PI3K/PTEN) is known to heavily influence cell growth, survival, proliferation, and various other cell cycle regulation events. The roles of the PI3K/PTEN pathway has not been explored in U. maydis. Altering candidate genes for PI3K and PTEN in U. maydis may provide insight into their function and roles in regards to pathogenicity and cell survival. Mating, cell viability, and infection assays 
were performed in order to determine the roles of the candidate genes functioning on pathogenicity. Disrupting or overexpressing these genes appears to have no effect on pathogenicity, survival, morphology, and proliferation. 


\section{TABLES OF CONTENTS}

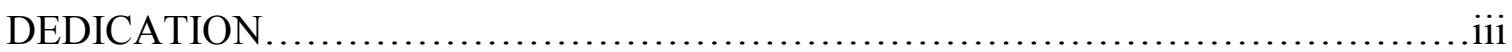

ACKNOWLEDGMENTS .......................................................

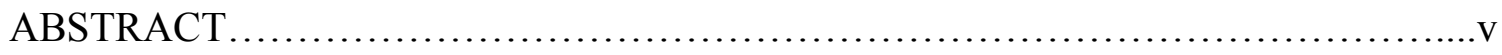

LIST OF TABLES ..........................................................ii

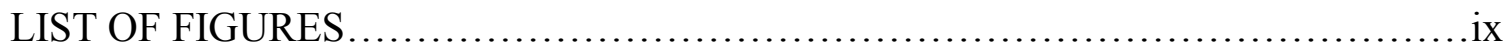

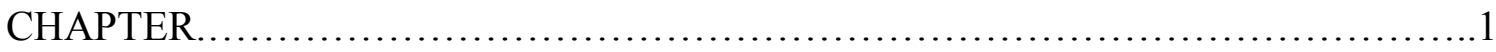

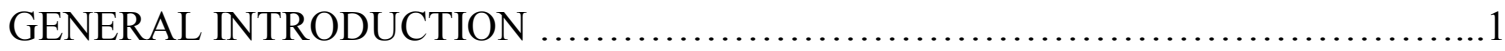

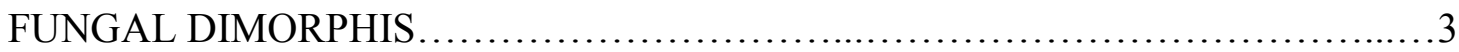

FUNGAL PATHOGENS ......................................................

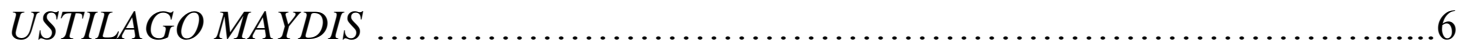

LIFECYCLE OF USTILAGO MAYDIS .....................................

MATING TYPES IN USTILAGO MAYDIS .................................. 8

SIGNAL TRANSDUCTION PATHWAYS ..................................

MEMBRANE RECEPTORS AND SIGNALING PROTEINS ........................11

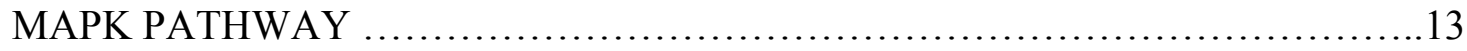

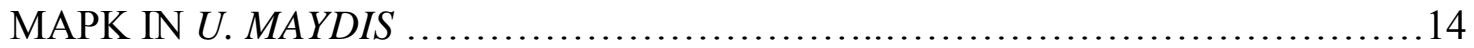

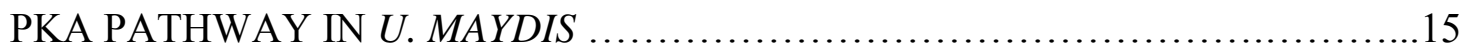

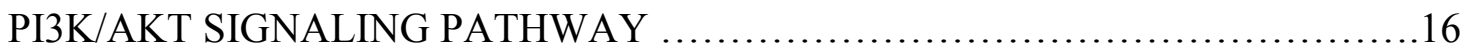

PTENS ROLE IN PI3K PATHWAY AND CANCER ...........................20

INITIAL RESEARCH INTEREST OF THESIS ..................................21

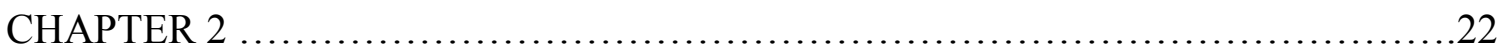

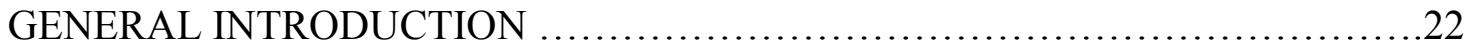

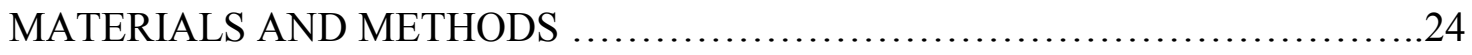


STRAINS AND GROWTH CONFITIONS ................................24

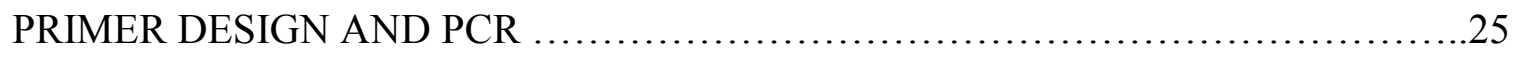

GENETIC MANIPULATION AND VECTOR CONSTRUCTION ...............26

CELL VIABILITY ON STRESS MEDIA ...................................27

MATING ASSAY AND PLANT INFECTION ..............................27

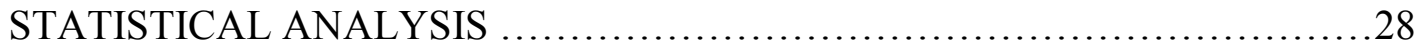

RESULTS ............................................................ 28

MATING EFFICIENCY IN U.MAYDIS MUTANTS ..........................28

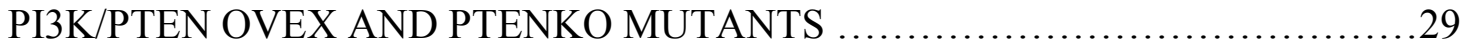

STRESS VIABILITY IN $U$. MAYDIS MUTANTS ............................29

PATHOGENICITY IN $U$. MAYDIS MUTANTS ..................................

PI3K/PTENOVEX AND PTENKO MUTANTS ...............................30

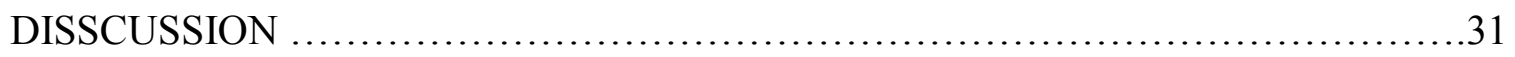

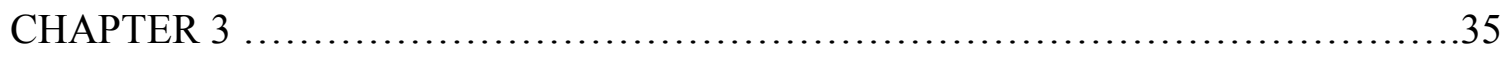

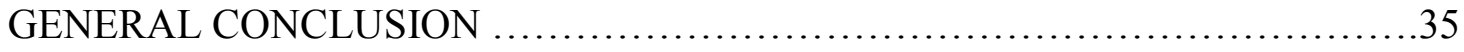

FUTURE DIRECTIONS .................................................

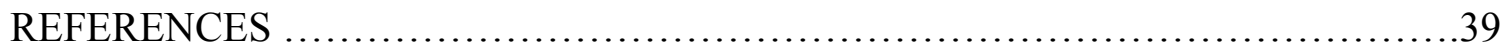

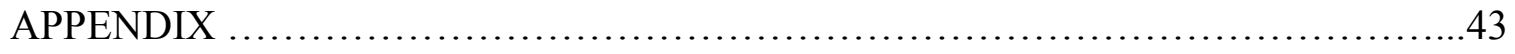

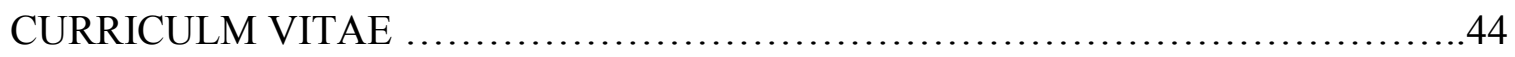




\section{LIST OF TABLES}

TABLE 1: ORIGIN AND GENOTYPES OF $U$. MAYDIS STRAINS ...................25

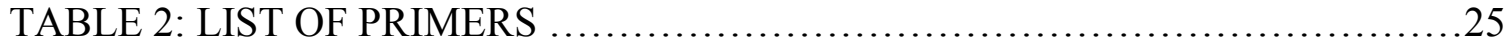

TABLE A: INFECTION SCORES OF PLANTS TAKEN JULY $14^{\mathrm{TH}} 2016 \ldots \ldots \ldots . . .43$

TABLE B: INFECTION SCORES OF PLANTS TAKEN AUG $16^{\mathrm{TH}} 2016 \ldots \ldots \ldots \ldots . . . .43$

TABLE C: INFECTION SCORES OF PLANTS TAKEN JUNE $4^{\mathrm{TH}} 2016 \ldots \ldots \ldots \ldots . . . .43$ 


\section{LIST OF FIGURES}

FIGURE 1: LIFECYCLE OF USTILAGO MAYDIS ..................................

FIGURE 2: MATING-TYPE INTERACTIONS DURING U.MAYDIS

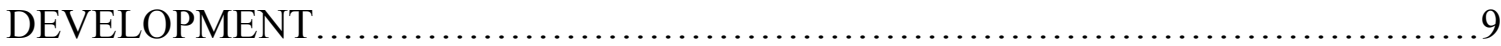

FIGURE 3: MAPK SIGNALING CASCADE IN U. MAYDIS .........................14

FIGURE 4: ILLUSTRATION OF $U$. MAYDIS PATHWAY/PKA PATHWAY .........16

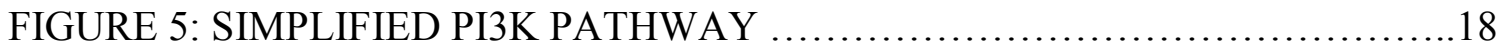

FIGURE 6: MATING EFFICIENCY IN U. MAYDIS MUTANTS 24/48HR ............28

FIGURE 7: PTENKO AND PTENOVEX MUTANTS CONGO RED PLATE..........30

FIGURE 8: INFECTIONS ......................................................

FIGURE 9: BAR GRAPH OF INFECTED SCORES IN PLANTS JULY $14^{\mathrm{TH}} 2016 . .31$ 


\section{CHAPTER 1}

\section{GENERAL INTRODUCTION}

Fungi consist of a broad range of living organisms that are classified as eukaryotes under their own kingdom in relation to the biological classification system (Whittaker, 1969). Fungi play essential roles in ecological systems, acting as decomposers of organic matter to help the cycling of essential nutrients in their environments as well as serving as symbionts with animals, plants, and other fungi (Simpson and Roger, 2004). The total number of fungal species on the planet isn't known, but the most recent calculations of fungi to vascular plant ratios using environmental DNA from soil samples have estimated that there are anywhere from 3.5 to 5.1 million global soil fungal species, of which roughly 99,000 have been identified (Hawksworth, 2001; O'Brien et al., 2005).

Numerous fungi provide significant benefits to humans, such as Saccharomyces cerevisiae, commonly known as yeast, which has been used for centuries for baking bread and is a critical component in the fermentation process of brewing alcoholic beverages (Legras et al., 2007). Some fungi possess important medicinal qualities such as providing antimicrobial activity or the possibility to reduce the risk of breast cancer (Alves et al., 2012; Froufe et al., 2011). The fungus Grifola frondosa has even been linked with the ability to lower blood pressure (Nanba et al., 1994). 
The phylogentic history of fungi has been researched extensively and, in the past, was a hotly debated topic, as fungi share similar traits with both plants and animals. Before the development of molecular methods for determination of phylogenetic relationships, fungi were considered to be a part of the plant kingdom due to the obvious similarities of being immobile, possessing cell walls (although of a different composition), and their nature of growing predominantly in soil. In recent years, modern technological advancements have allowed for the analysis of nucleotide and amino acid sequences of fungi and have shown that fungi are more closely related to animals rather than plants (Baldauf and Palmer, 1993; Feofilova, 2001). These phylogenetic studies have been key in tracing back the evolutionary paths of organisms and have been able to show the relationship between fungi and animals evolutionary origins, linking them to a flagellate protozoa as a single common ancestor (Cavalier-Smith and Chao, 1995). Over the past few decades our understanding of evolutionary relationships has deepened, prompting the formation of unique clades called "super-groups" that aim to help characterize these evolutionary relationships of microbial lineages (Parfrey et al., 2006). Subsequently fungi, animals, and their microbial relatives such as choanoflagellates, have been placed into the super-group "Opisthokonta" in which the members share common molecular and cellular characteristics, most notably the possessing of a single posterior flagellum (Cavalier-Smith and Chao, 1995). These recent revelations suggest that fungi and humans might share more evolutionarily conserved characteristics than previously thought.

Fungi are heterotrophs like animals, meaning they cannot produce their own source of nutrients but rather have to obtain them from their surrounding environment 
(Taylor and Osborn, 1996). Unlike animals, which ingest their nutrients, fungi obtain their nutrients from the outside environment usually by secreting hydrolytic enzymes that break down organic matter which they can then absorb. Fungal life cycles differ between different species and historically have been divided into two distinct groups known as 'Fungi Imperfecti' and 'Fungi Perfecti'. The group of fungi labeled 'Fungi Imperfecti', sometimes informally referred to deuteromycetes (Guarro et al., 1999), refers to fungi that have only been observed reproducing asexually through mitosis. The subkingdom of fungi known as the Dikarya is comprised of two phyla, Basidiomycota and Ascomycota, and is often referred to as 'Fungi Perfecti' or “higher fungi”' (Lutzoni et al., 2004).

Dikarya reproduce both sexually and asexually and are characterized by their ability to produce dikaryons, a feature that allows a portion of a cells lifecycle to share two distinct nuclei (James et al., 2006). The ability to undergo both asexual and sexual reproduction is also referred to as anamorphic and telomorphic reproduction, respectively (de Hoog et al., 2000).

\section{FUNGAL DIMORPHISM}

A large number of fungal species possess the evolutionarily conserved ability of dimorphism. Dimorphism allows the cells to undergo a dramatic switch in their lifecycle from a single celled yeast-like form to a filamentous, sometimes multicellular, form depending on environmental conditions that vary between species (Sánchez-Martínez and Pérez-Martín, 2001). In the yeast like form, fungal cells divide via mitosis and produce completely independent cells. The filamentous form is characterized by the production of hyphae which consist of tubular cell walls that surround the cells. Hyphae are typically divided via cross-walls known as septa that are connected through large pores that allow 
for open flow between cells (Alexopoulos, 1952). These hyphae branch out, growing from their tips, and form a filamentous web like mass known as mycelium which fungi use to absorb their nutrients.

Unlike plant cell walls which contain cellulose, fungal cell walls are comprised of a nitrogen-containing polysaccharide derivative of glucose called chitin (Kumar, 2000).

S. cerevisiae produce hyphae-like filamentation under stressful environmental conditions in which cells divide but fail to separate after undergoing cytokinesis, leading to a long continuous chain of attached cells known as pseudohyphae (Nadal et al., 2008). In many fungi, the ability to undergo this dimorphic switch is necessary in order to respond and adapt to unfavorable environmental conditions such as low nutrients, temperature change, and oxygen levels. Many parasitic fungi utilize this morphogenic strategy in order to switch between saprophytic and pathogenic lifecycle phases (Nadal et al., 2008).

\section{FUNGAL PATHOGENS}

Although the majority of fungal species act as saprotrophs by decomposing plant and animal tissues to obtain nutrients from dead and decaying organic matter, there are a large number of fungal species that are pathogenic and require infection of a host in order to complete their lifecycle. Plant pathogens are classified as being either necrotrophs, biotrophs, or hemibiotrphs according to their host invasion strategies (GonzálezFernández et al., 2010). Necrotrophs kill the infected host tissues and derive nutrients from the dead contents, whereas biotrophs leech nutrients from the host and complete their lifecycle within the host without requiring the death of the plant tissues (Dangl and Jones, 2001). Hemibiotrophs are unique as they act in sequential phases, the first phase 
being biotrophic followed by a second necrotrophic phase for nutrition (GonzálezFernández et al., 2010).

Fungal pathogens have directly and indirectly had negative impacts on human life, causing disease in both animals and plants alike. There are an estimated 15,000 fungal species that cause diseases in plants (González-Fernández et al., 2010; Taylor and Osborn, 1996). Fungal plant pathogens are responsible for the most damage economically in crop plants over any other group of microorganisms, with the cost of losses exceeding 200 billion US dollars annually as well as 600 million dollars spent a year in the US alone on preventative fungicides (González-Fernández et al., 2010; Horbach et al., 2011). The well-known filamentous ascomycete fungal pathogen Mangaporthe oryzae, commonly referred to as rice blast disease, is considered to be the most devastating disease that infects rice worldwide $(\mathrm{Ou}, 1980)$. Annual rice crop losses due to infection of M. oryzae range anywhere from $10 \%$ to $30 \%$ which amounts to enough to feed roughly 60 to 180 million people annually (Skamnioti and Gurr, 2009). The fungus Botrytis cinerea can infect over 200 species of plants and results in an immeasurable amount of crop damage per year due to the wide range of species it infects. Fungicides that specifically target Botrytis are known as 'botryticides' and make up about $10 \%$ of the fungicide market worldwide totaling around 540 million euros (Dean et al., 2012).

The attempt to understand fungi and their characteristics has fueled scientific research, helping to contribute to the understanding of many important biological processes. Pioneering research first demonstrating homologous recombination involving 'Holliday junctions' was conducted using the model organisms S. cerevisiae and the fungal pathogen Ustilago maydis (Holliday, 1964). The model organism S. cerevisiae is 
the most well understood and studied eukaryote due to the fact that it is easily maintained in a laboratory setting and can be genetically manipulated fairly easily. However, the need to find a more appropriate fungus as a model organism with relevance to humans arose due to the fact that ascomycete fungi lack specific cellular processes that are shared among many eukaryotes, including humans, such as nuclear envelope dynamics in open mitosis. Along with its relative ease to maintain in a laboratory environment, U. maydis has been shown to be possess certain cellular processes common to "higher" eukaryotes, such as open mitosis, motor protein based growth, and microtubule-based long distance transporting of RNA (Steinberg and Perez-Martin, 2008). In addition, its genome has been sequenced and is publicly available (Kämper et al., 2006) and as such, has made it an appropriate and popular model organism to study the fundamentals of cellular mechanics.

\section{USTILAGO MAYDIS}

Commonly referred to as corn smut, U. maydis is a dimorphic fungal pathogen that infects maize (Zea mays) and teosonite (Zea mexicana). First described in 1815 by Swiss botanist Augustin de Candolle, U.maydis is a part of the Basidiomycota phylum of fungi under the subkingdom Dikarya. Infection of its host is characterized by the formation of large tumor-like galls that grow on the stem, leaves, and flowers of the infected plant (Bölker, 2001). Although corn smut is considered an agricultural threat to US corn crops, with $1 \%$ annual losses, costing roughly $\$ 189$ million per year (MartínezEspinoza et al., 2002), it is considered a staple delicacy known as "Huitlacoche" in Mexican cuisine. The mushroom-like galls produced by infection have been harvested for 
consumption for centuries in Mesoamerica, dating as far back to the times of the Aztecs (Ruiz-Herrera and Martínez-Espinoza, 2010).

\section{LIFECYCLE OF USTILAGO MAYDIS}

$U$.maydis is a biotrophic fungus with a complicated lifecycle (Figure 1) in which infection of a living host is obligate in order to complete sexual reproduction and spore production (Bölker, 2001). In its non-pathogenic saprophytic haploid state, basidospores (sporidia) undergo mitoic cell division by polar budding, these cells may "search" for a compatible mating partner outside of the plant. Propagating haploid cells can be maintained easily on artificial media for use in a laboratory setting. Upon finding a compatible mate via a pheromone-receptor system, haploid cells form conjugation tubes and fuse to form a filamentous dikaryon that contains the two separate nuclei from the parent cells. These dikaryons are unique in that the two nuclei have yet to undergo nuclear fusion (Karyogamy).

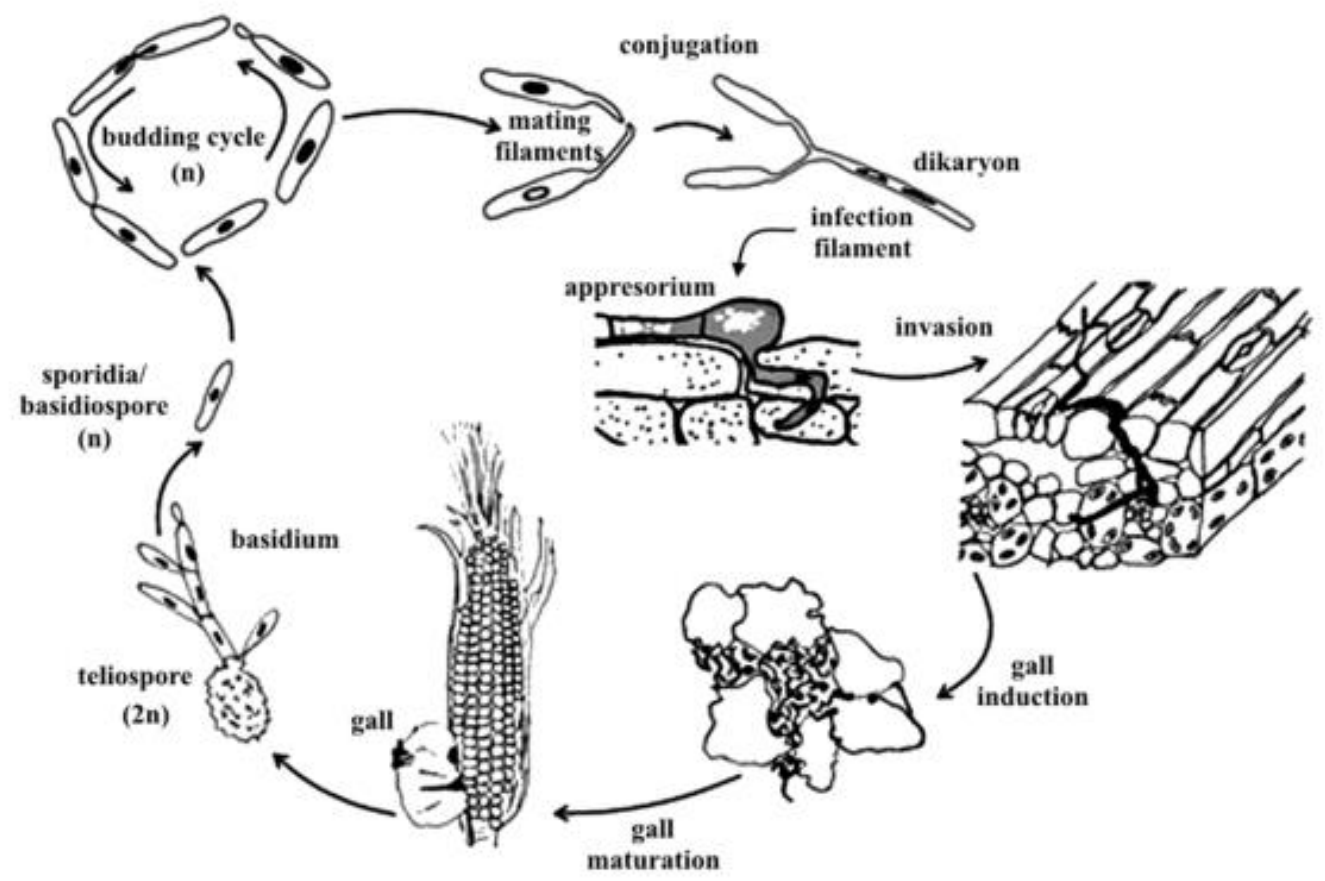

Figure 1: Lifecycle of Ustilago maydis. (Pataky and Snetselaar, 2006) 
In the presence of a host, dikaryotic hyphae form a specialized infection structures called appressoria that are commonly found in fungal pathogens (Howard et al., 1991).

These appressoria act to penetrate the plant surface typically utilizing osmotic turgor pressure (Howard et al., 1991), although for U. maydis they are likely the source for secreted plant cell wall degrading enzymes (Kämper et al., 2006). Gall formation results from plant cell proliferation that is promoted by the fungus. Inside the galls, the dikaryotic fungal cells undergo karyogomy to produce diploid teliospores. Eventually the galls mature and rupture, releasing the teliospores out into the environment. Once favorable conditions are met the teliospores germinate, undergoing meiosis and forming a promycelium that produces haploid sporidia (Klosterman et al., 2007).

\section{MATING TYPES IN USTILAGO MAYDIS}

Mating of the haploid cells leading to formation of the dikaryon is essential for $U$. maydis to carry out infection and complete its lifecycle. This dimorphic switch is controlled by a tetrapolar mating system governed by two unlinked mating loci (MAT), $a$ and $b$, that are located on separate chromosomes. The $a$-locus has two idomorphs, $a l$ and $a 2$, that both contain genes encoding a secreted mating pheromone a ( $\mathrm{mfa} 1 / 2)$ and a $\mathrm{G}$ protein-coupled pheromone receptor (pra1/2) used in self, non-self recognition. The $a 1$ locus also encodes Right Border a protein 1 (Rba1) which is thought to target to mitochondrial membrane and the $a 2$ locus encodes two mitochondrial proteins Lga 2 and Rga2, as well as a pseudogene rba2 (Schirawski et al., 2005). Studies focusing on the $\lg a 2$ and $r g a 2$ genes from the $a$ locus have demonstrated their involvement in determining mitochondrial inheritance in daughter cells (Brefort et al., 2009). Survival, growth, and pathogenicity are dependent on products of the $b$-mating locus. The $b$ locus 
has more than 25 different alleles and is located on chromosome 5. Encoded in the $b$ locus are two different genes for homeodomain proteins $\mathrm{bE}$ and $\mathrm{bW}$, which upon pairing together form a heterodimeric transcriptional factor, if derived from different alleles.

The $\mathrm{bE}$ and $\mathrm{bW}$ proteins, respectively, contain 410 and 626 amino acids and, similar to the $a$ locus proteins, are also involved in self/non-self recognition during mating. The functional heterodimer between $\mathrm{bE}$ and $\mathrm{bW}$ forms only if the proteins come

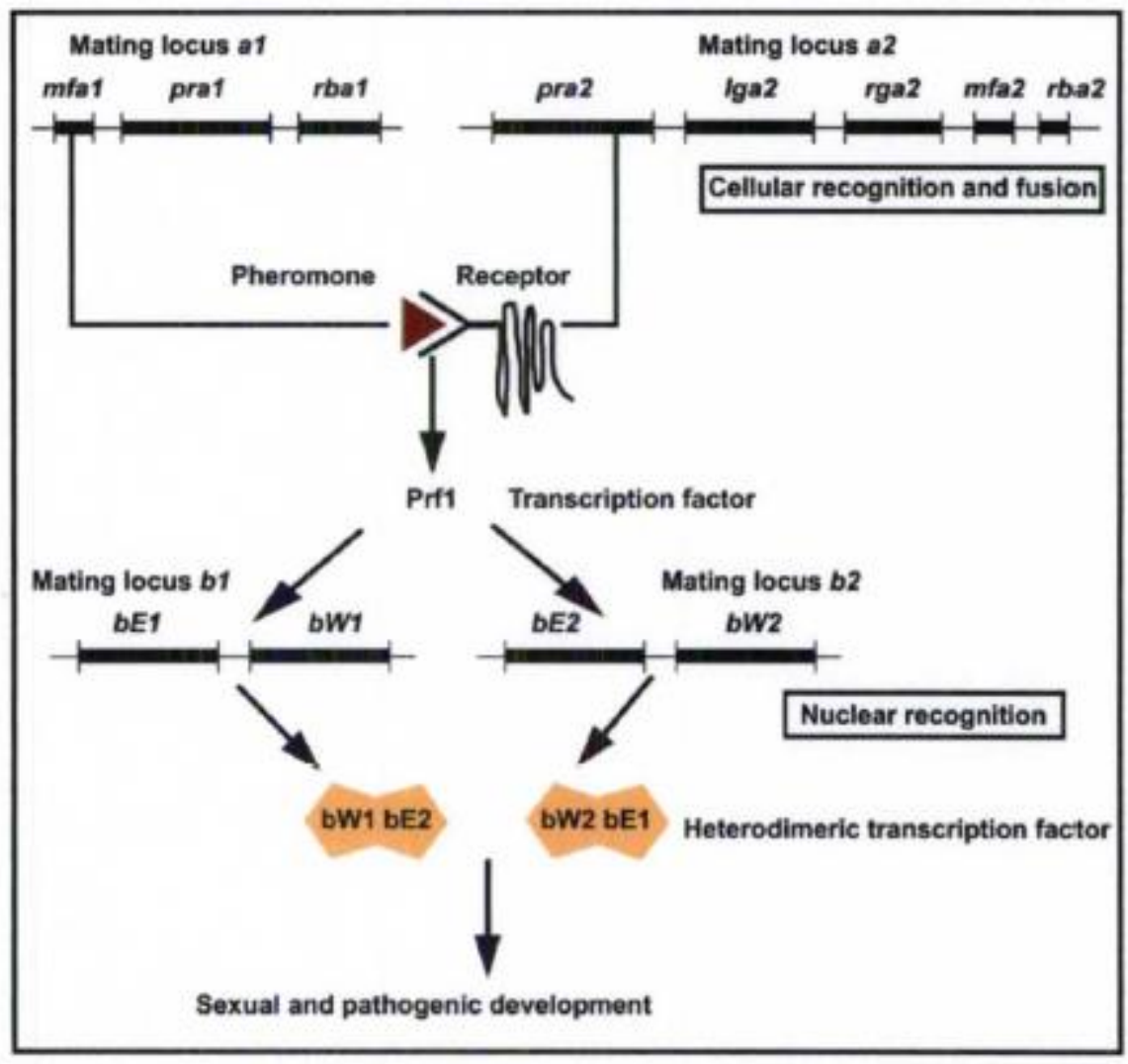

Figure 2: Mating-type interactions during $U$. maydis development. Adapted with permission from (Bölker, 2001).

from different $b$ alleles (Figure 2) (for example bEl-bW2 or bE2-bW1, but not bE1-bW1 or bE1-bE2) (Kämper et al., 1995). This allele specific recognition between $b$ proteins is carried out by a variable $\mathrm{N}$-terminal region of approximately 100 amino acids. The formed heterodimer is a functional transcription factor that contains a homeodomain 
motif that binds to DNA and can trigger the expression of over 246 genes involved in pathogenicity (Kahmann and Kämper, 2004). These mating interactions require signals from the host plant to release the dikaryon from cell-cycle arrest associated with the pheromone response system in order to continue its lifecycle and subsequent infection (García-Muse et al., 2004; Nadal et al., 2008). The morphogenetic transitions, environmental signal integrations, and mating regulations in organisms have been shown to involve a number of different signal transduction pathways, such as the mitogen activated protein kinase (MAPK), cAMP-dependent protein kinase A (PKA) pathways. Another pathway important in these processes is the phosphatidylinositol-4,5 bisphosphate 3-kinase/ protein kinase b pathways (PI3K/Akt) which has yet to be explored in $U$. maydis.

\section{SIGNAL TRANSDUCTION PATHWAYS}

The most studied signal transduction pathways in fungi involving cell division, growth and differentiation, filamentous response, and environmental stress response are the MAPK and cAMP-dependent PKA pathways. The MAPK pathway, also known as the Extracellular signal-Regulated Kinase (ERK) pathway, is conserved among eukaryotes, including yeast and humans. It is involved in a multitude of cellular processes including mating and filamentation (Tudzynski and Sharon, 2003). The core model of the pathway is characterized by a series of three cascading phosphorylation events triggered by different protein kinases, MAPKK kinase (MEKK/MAPKKK), MAPK kinase (MAPKK/ERK kinase [MERK]), and MAP kinase (MAPK or ERK) (Bardwell, 2005). These pathways are usually activated by specific receptors such as G-protein coupled 
receptors (GPCRs), receptor tyrosine kinases (RTKs), or various other membrane receptors which are mentioned later.

\section{MEMBRANE RECEPTORS AND SIGNALING PROTEINS}

Signaling cascades are able to detect stimuli such as pheromones and nutrient levels, allowing dimorphic fungi to undergo specific phase transitions (Pham et al., 2009). Important components of signaling pathways are their specific receptors and signaling proteins. These cellular signaling pathways are activated by a multitude of extracellular ligand molecules that interact to activate different receptors. Common to many signaling cascades are GPCRs. If a membrane receptor is associated with a $\mathrm{G}$ protein or small GTP-binding proteins, then the protein is conventionally considered a GPCR. These seven-transmembrane domain receptors activate G proteins in order to coordinate specific biological processes involved in signaling cascades. In eukaryotes, there are five main families of small G-proteins that control a wide variety of cellular processes: Ras, Rho, Rab, Arf and Ran (Wennerberg et al., 2005). Ras family proteins regulate signaling pathways which result in transcription and cellular differentiation and proliferation. Ran proteins are involved in nuclear export and import as well as nuclear envelope and spindle formation. Rho family proteins are mainly involved with cytokinesis, cellular shape, and migration. Rab and Arf G protein familes are an important part of vesicle-associated processes such as formation and transport. (Bos et al., 2007). Previous studies have shown that $U$. maydis has six different Rho/Rac encoding genes, two of which have been studied in depth (Cdc42 and Rac1) (Kämper et al., 2006). Cdc42 has been shown to play a role in cytokinesis regulation while Rac1 is 
involved with hyphal development regulation. The two of these proteins as well as a ubiquitously expressed 14-3-3 protein, of which $U$. maydis has a single homologue of named Pdc1, are involved in regulatory cascades that control morphogenesis in $U$. maydis (Leveleki et al., 2004; Pham et al., 2009).

In their active form, $G$ proteins interact with effector proteins to induce signaling events downstream, switching between inactive GDP-bound and active GTP-bound conformations via guanine exchange factors (GEFs). There are two main classes of $\mathrm{G}$ proteins, monomeric small GTPases and heterotrimeric G protein complexes. For the latter, the $\mathrm{G}$ protein complexes consist of alpha, beta, and gamma subunits that disassociate from the receptor when an appropriate ligand binds to the receptor to cause a conformational change that induces the GEFs to turn the G protein "on". These 'OFF' and 'ON' guanine switches are tightly regulated by GDP Dissociation Inhibitor proteins (GDI) and GTPase activity that is turned 'ON' once the G-proteins and small G-proteins are activated, leading to the hydrolysis of GTP to GDP (Takai et al., 2001).

Another common group of membrane receptors involved in signaling cascade activation are receptor tyrosine kinases (RTKs). There are many families of RTKs such as epidermal growth factor receptors (EGFRs), fibroblast growth factor receptors (FGFRs), Insulin receptors, and many more. In humans, RTKs are essential components during embryonic development and adult homeostasis (Hubbard and Miller, 2007). RTKs are usually monomeric until the appropriate ligands bind to them to promote dimerization. Upon dimerization, tyrosine residues associated with the monomers are trans-phosphorylated by the protein kinase activity of the partner receptors in most RTKs. This phosphorylation event occurs by first phosphorylating tyrosine residues near 
the catalytic site of the protein kinase associated with the receptor monomer which in turn causes a conformational change that facilitates binding of ATP and other protein substrates. The receptor kinase activity can then phosphorylate other sites in which the phosphorylated tyrosines can serve as docking sites for various proteins involved in RTK signal transduction (Berk et al., 2000).

\section{MAPK PATHWAY}

In $S$. cerevisiae, the MAPK cascade exists but it is more complex than the core model, consisting of several extra components upstream and downstream of the phosphorylation events. When mating occurs between opposite mating types, a pheromone is recognized by a pheromone receptor of the opposite mating type. The seven-transmembrane domain pheromone receptor, Ste2 (Ste3 in the other mating type), is coupled to a trimeric $\mathrm{G}$ protein and upon activation, triggers the heterotrimeric $\mathrm{G}$ protein to disassociate into $\mathrm{G \alpha}$ and $\mathrm{G} \beta \gamma$ subunits. The G $\beta$ y subunit consisting of Ste18 and Ste4 activate the pathway by binding to both p21-activated kinase (PAK) Ste20 and to Ste 5, the scaffolding protein that acts to hold together the multiple components of the MAPK. Binding to Ste20 activates Ste11 (MEKK) via phosphorylation which in turn activates Ste7 (MAPKK), which phosphorylates and activates Fus3 (MAPK). Fus3 acts to repress Dig1/2 which is a negative regulator of transcription factor Ste12, subsequently activating it and allowing for transcription of pheromone response mating genes (Bardwell, 2005). Fus3/Kss1 also activates another transcription factor, Far1, which mediates cell cycle arrest. The MAPK pathway is also used to regulate filamentation with response to environmental stress such as nutrient limitation. The signaling cascade remains as previously described except the Kss1 MAPK is used instead of Fus3 to allow 
Ste12 to associate with the transcription factor Tec $1 \mathrm{p}$ that is associated with filamentous response. The main difference is that there are multiple different receptors that act together to activate the filamentation response (Chen and Thorner, 2007). There are many different signal cascade responses of the MAPK pathway in yeast which are not fully understood but it seems that Ste20 is a common mediator in each route.

\section{MAPK IN $U$. MAYDIS}

U. maydis has a MAPK cascade

pathway (Figure 3) involved with pheromone response that is similar to $S$. cerevisiae, although it is not completely understood. The pathway starts with the Mfa1 (or Mfa2) pheromone binding to the proper G-protein coupled receptor Pra2 (or Pra1). The next step of the pathway isn't exactly known but some evidence shows that Ras2, a small G-protein, is activated and disassociates from the receptor complex and might possibly interact with a Smu1, an Ste20 homologue, and Cdc42 to

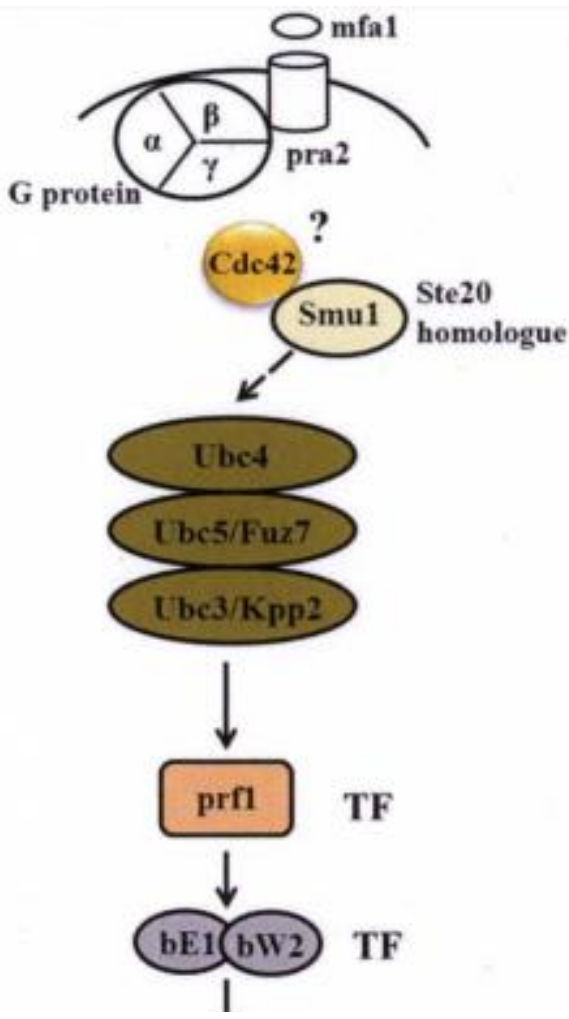

Figure 3: MAPK signaling cascade in $U$. maydis (Paul, 2011).

relay signals down the cascade (Smith et al., 2004). The core phosphorylation cascade in U. maydis consists of MAPKKK Ubc4 (kpp4), MAPKK Ubc5 (Fuz7), and MAPK (kpp2/Ubc3 and Kpp6). Kpp6 has been shown to be redundant to Ubc3 but is essential for pathogenicity and is involved with penetrating plant tissue (Brachmann et al., 2003). Ubc2, which stands for Ustilago Bypass Cyclase, acts as the scaffolding protein similar 
to Ste50 in yeast. Similar to yeast, the MAPK pathway in U. maydis activates downstream transcription factors. Phosphorylation occurs for the transcription factor Prf1 and the Ser/Thr kinase,Crk1, with both leading to induction of the mating loci components. Prfl also has phosphorylation sites that are targets for the protein kinase A pathway (PKA) which is described below. Induction of $a$ and $b$ genes requires PKA and MAPK sites on Prf1 (Kaffarnik et al., 2003).

\section{PKA PATHWAY IN U. MAYDIS}

The PKA pathway is dependent on cyclic AMP (cAMP) and along with the MAPK pathway, contributes to the activation of the $a$ and $b$ mating loci. It is composed of enzymes that manipulate cAMP levels to regulate cellular responses to stresses such as nutrient limitations (Lengeler et al., 2000). The core components of the PKA pathway consist of adenylate cyclase (AC) and the heterodimeric PKA module. The PKA module is comprised of a regulatory and a catalytic subunit in which the regulatory subunit acts to repress the functioning catalytic subunit. The activity of the PKA module is influenced by intracellular cAMP levels; environmental cues influence the G protein coupled membrane receptor so as to activate adenylyl cyclase to generate cAMP from ATP. When cAMP is present, it binds to the regulatory subunits, causing them to disassociate, thereby allowing for the catalytic subunit to function. Levels of cAMP in U. maydis are regulated by the phosphodiesterases Pde1 and Pde2 and therefore control the activity of the PKA pathway (Agarwal et al., 2010). The subunit of the heterodimeric G-protein Gpa3 disassociates from the GPCR upon appropriate environmental cues and activates the Uac1 (Ustilago Adenylate Cyclase) enzyme so as to increase cAMP levels. cAMP binds to the regulatory subunit Ubc1 (Ustilago Bypass Cyclase1) and alters the conformation, 
resulting in the release of the catalytic subunit Adr1/Uka1 which promotes PKA activity (Kahmann and Kämper, 2004). It has been observed that under low ammonium conditions, cAMP levels are low in $U$. maydis and cause filamentous growth dependent

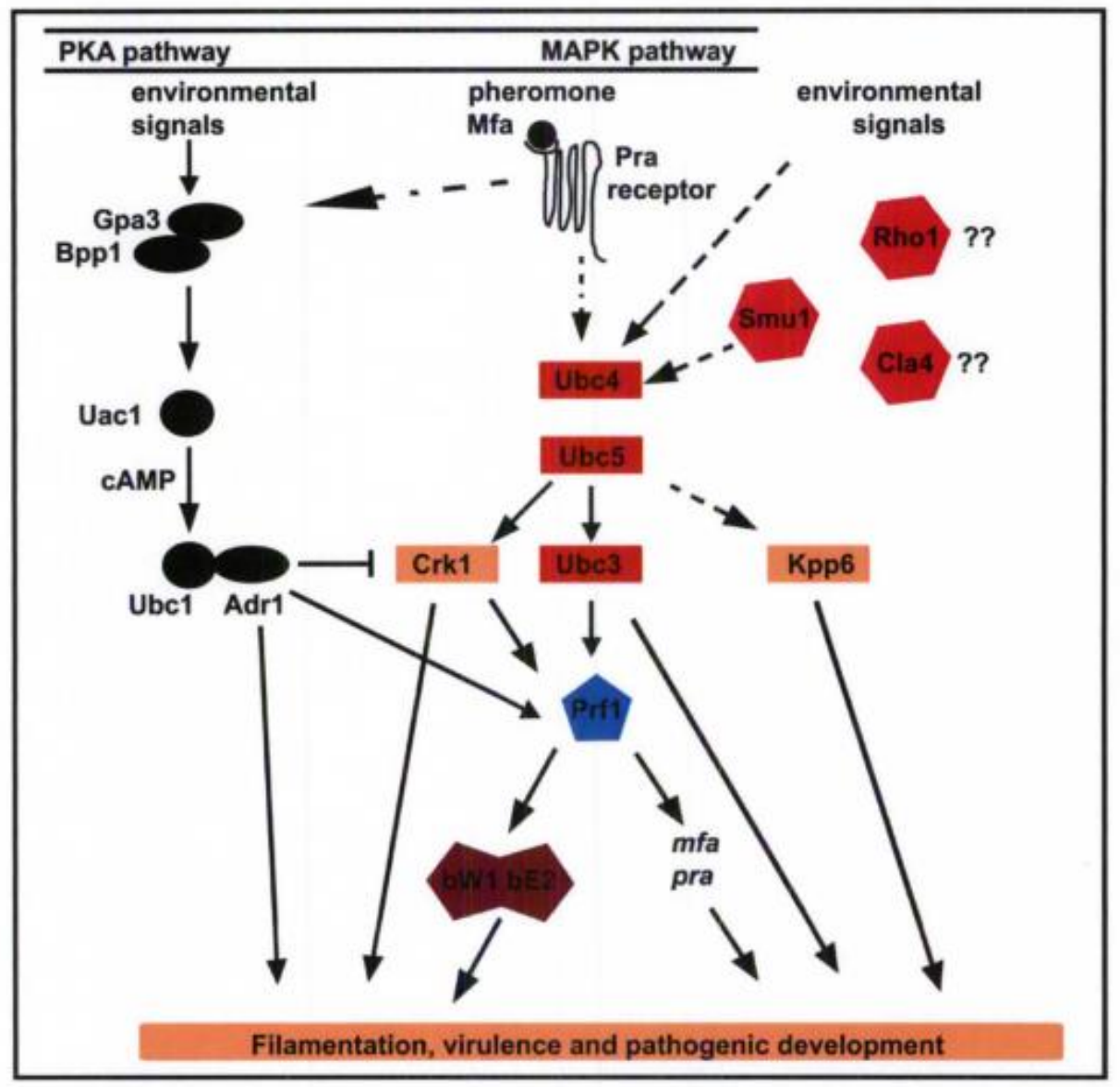

Figure 4: Illustration of $U$. maydis MAPK pathway (Mitogen activated pathway) on right and PKA pathway (Protein Kinase A) on left. Adapted from (Kahmann and Kämper, 2004)

on the PKA pathway (Smith et al., 2003). Further study into these and other pathways in U.maydis and other organisms is crucial to elucidating their specific roles when responding to various internal and external stimuli.

\section{PI3K/AKT SIGNALING PATHWAY}


Although much of the research on pathogenicity and cell growth in fungi has focused mainly on the MAPK and PKA signal pathways, another important pathway in all higher eukaryotic systems is the phosphoinositide 3-kinase/protein kinase B

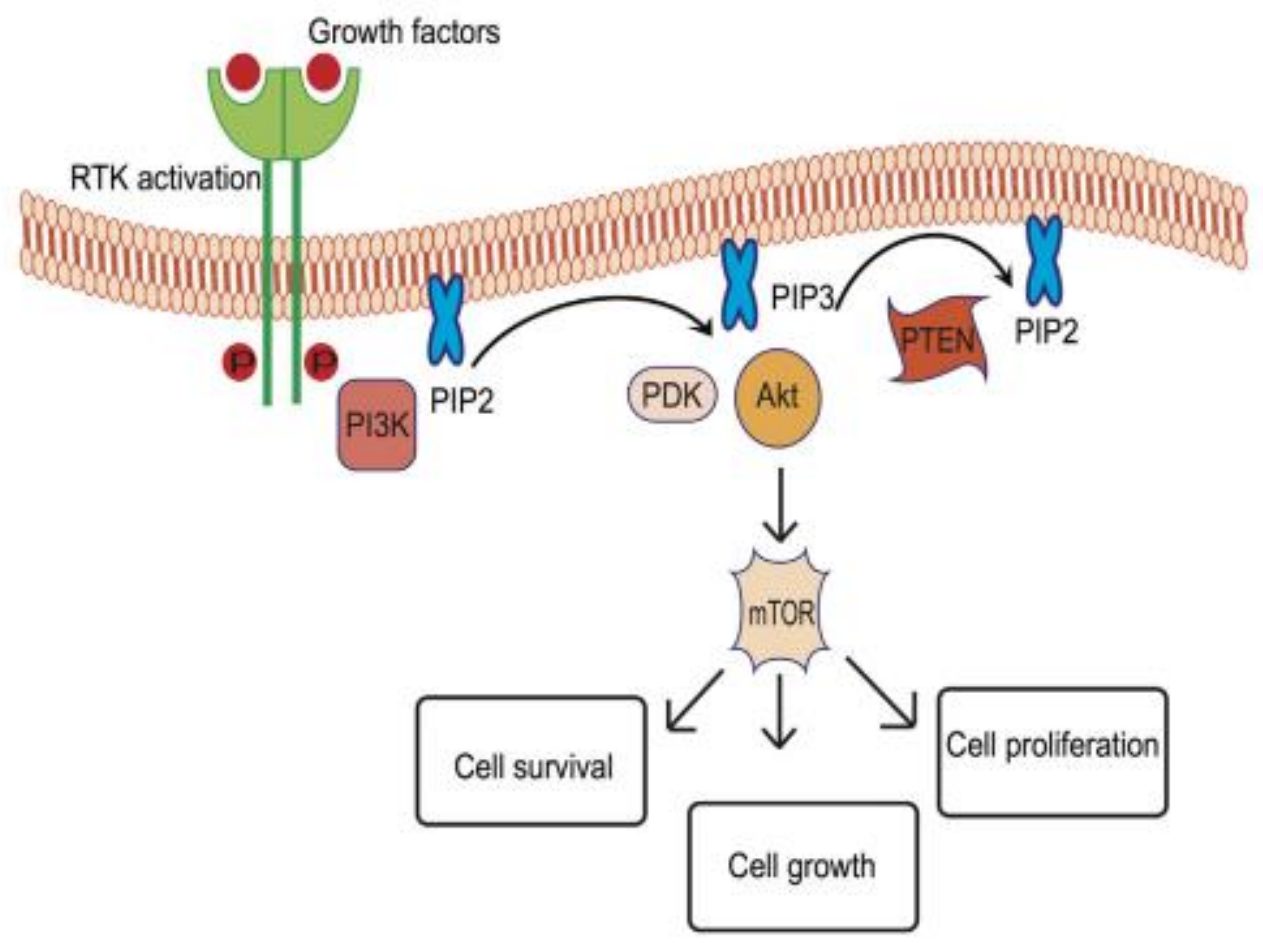

Figure 5: Simplified PI3K pathway. Adapted from (Yadav et al., 2015)

(PI3K/Akt/mTOR) pathway which is directly associated with cell cycle regulation (Manning and Cantley, 2007). The PI3K/Akt/mTOR pathway in mammalian systems is known to be associated with cell growth, proliferation, motility, survival, lipid signaling, intracellular trafficking, and many other cellular processes (Figure 5) (Paez and Sellers, 2004; Vara et al., 2004). Understanding this pathway has been an area of interest for human biology as mutations involved with this pathway have been shown to be common in many forms of cancer (Paez and Sellers, 2004). The PI3K pathway (Figure 5) is, generally, a proliferation-promoting signaling pathway involving a family of signal 
transducer enzymes called PI3Ks. Various signals including growth factors, insulin, and oxidative stress are responsible for activation of the pathway. Three types of transmembrane receptors known to act in response to activation signals in this pathway are GPCRs, insulin receptors (INSRs), and receptor tyrosine kinases (RTKs) (Hutz, 2010). Upon receptor activation, PI3K is able to phosphorylate the 3' position hydroxyl group on phosphatidylinositol (Ptdlns) allowing the conversion of phosphatidylinositol 4,5-bisphosphate $\left(\mathrm{PIP}_{2}\right.$ or PtdIns(4,5) $\left.\mathrm{P}_{2}\right)$ into phosphatidylinositol 3,4,5-triphosphate $\left(\mathrm{PIP}_{3}\right.$ or PtdIns3,4,5) $\mathrm{P}_{3}$. $\mathrm{PIP}_{2}$ and $\mathrm{PIP}_{3}$ are phospholipids located in the plasma membrane that act as substrates for various signaling proteins. These phosphoinositide lipids play important roles in various processes such as cell signaling, lipid signaling, and membrane trafficking (Jean and Kiger, 2014).

The activation and subsequent dimerization and cross-phosphorylation of RTKs activate the PI3K pathway. A regulatory subunit, p85, binds to the phosphorylated tyrosine sites on the activated RTK by interacting with a Src homology 2 (SH2) domain (Bafico and Aaronson, 2003). It is then able to recruit the catalytic subunit of PI3K, p110, in order to catalyze the reaction from $\mathrm{PIP}_{2}$ to $\mathrm{PIP}_{3}$. Another adaptor molecule, Grb2, binds to specific motifs on the RTK and recruit p85 through Grb2-associated binding (GAB) scaffolding protein. Alternatively, Grb2 can also bind a Ras-GEF (Sos1) to activate Ras, so that Ras-GTP can then activate the p1 10 subunit of PI3K (Castellano and Downward, 2011). PI3K can also be activated by other receptors, such as GPCRs, by interacting with various G-protein dimers or Ras proteins. Also, the G-alpha subunit activates Srcdependent integrin signaling which can activate PI3K. (New and Wong, 2007). 
The most notable function of $\mathrm{PIP}_{3}$ is activating the downstream signaling component Akt (Protein kinase B) which is a serine/threonine-specific protein kinase (Song et al., 2005). $\mathrm{PIP}_{3}$ is able to recruit the Akt protein to the plasma membrane due to the fact that Akt contains a specific PH (pleckstrin homology) domain that interacts preferentially with $\mathrm{PIP}_{3}$ (Frech et al., 1997). Akt then gets phosphorylated by two kinases, PDK1 and mTORC2, on sites T308 and S473, respectively, to become fully activated. Studies have also shown phosphoinositide-dependent kinase 2 (PDK2), integrin-linked kinase (ILK), DNA-dependent protein kinase (DNA-PK), and mechanistic target or rapamycin complex (mTORC) can also phosphorylate the S473 site of Akt (Hemmings and Restuccia, 2012; Vanhaesebroeck and Alessi, 2000). The activated form of Akt is responsible for modulating various components involved in cell-cycle progression. For example, Akt is able to directly and indirectly regulate cyclin dependent kinases (CDKs) $\mathrm{p} 27^{\mathrm{kip} 1}$ and $\mathrm{p} 21^{\mathrm{cip} 1}$, which are cell cycle inhibitors, to allow G1/S progression (Gao et al., 2014). Akt is also involved in many other processes such as phosphorylating proteins involved in the formation of the actin cytoskeleton. The Kank protein, which is a kidney Ankyrin repeat-containing protein, is a downstream substrate of Akt that regulates actin stress fibers and cell migration via the inhibition of RhoA. Kank has been shown to bind to $14-3-3$ proteins to negatively regulate the formation of actin fibers and cell migration in a process that is regulated by PI3K-Akt signaling (Kakinuma et al., 2008).

\section{PTENS ROLE IN PI3K PATHWAY AND CANCER}

Phosphatase and tensin homolog on chromosome ten (PTEN) is a protein encoded by a single gene in mammalian species. PTEN has a tyrosine phosphatase domain with dual protein and lipid phosphatase activity in vitro(Maehama and Dixon, 1998). The 
dephosphorylating activity of the lipid-phosphatase of PTEN is highly specific to phosphatidylinositol substrates, counteracting PI3Ks phosphorylation of PtdIns by removing the D3 phosphate from the inositol ring (Sulis and Parsons, 2003). Cells lacking PTEN have been shown to possess higher levels of PtdIns $(3,4,5) \mathrm{P}_{3}$. The loss of PTEN functionality results in a constitutively active PI3K pathway that builds up PIP3 levels which are associated with cell growth, division, and preventing apoptosis. Loss of PTEN functionality is related to tumor causing diseases such as Cowden Syndrome (Cantley and Neel, 1999) as well as many forms of human cancers.

PTEN somatic mutations are commonly found in human cancers such as endometrial, nervous system, skin, and prostate cancers (Chalhoub and Baker, 2009)and in many cases, they rival the frequency of p53 mutations that are one of the most infamous cancer causing mutations (Ali et al., 1999) Understanding fundamental PTEN/PI3K interactions and their role in activating the Akt pathway and other downstream activities are essential to developing possible therapeutic treatments for cancer and other diseases.

\section{INITIAL RESEARCH INTEREST OF THESIS}

The MAPK and cAMP-PKA signaling pathways in U. maydis have been a core focus of the Perlin lab over the past several years. Recently, the PI3K/Akt/mTOR pathway has become an area of interest for possible roles involving cellular signaling mechanisms and possible cross-talk and redundancy among other pathways. Both PI3K and its antagonist, PTEN, have been shown to be important components of this pathway 
that are conserved in many eukaryotes (Manning and Cantley, 2007), but these proteins have yet to be fully explored and characterized in fungi. The goal of this thesis was further study and evaluation of PTEN and PI3K homologues, to elucidate their functions in U. maydis and provide possible insights for other related fungi. Through genetic manipulation of the genes we will find out important characteristics associated with this pathway in U. maydis. Specifically, I hypothesized that constitutive upregulation or deletion of PI3K in U. maydis would directly influence cell proliferation, cell survival, and plant infection via the PI3K/Akt pathway. The presence or absence of the PI3K antagonist, PTEN, might also affect the ability of this the fungal pathogen to regulate the PI3K/Akt pathway by disrupting its ability to dephosphorylate PIP3 into PIP2. Previous studies utilizing the yeast 2-hybird screening method for testing protein-protein interactions have also shown a direct connection between PTEN homologue and essential signaling components Rho1 and the 14-3-3 homologue, Pdc1. Both Rho1 and Pdc1 physically interact with the PTEN homologue in U. maydis, indicating a possible role of PTEN in regulation of pseudohyphal growth, filamentation, cytokinesis and cell polarity (Pham et al., 2009). 


\section{CHAPTER II}

\section{GENERAL INTRODUCTION}

Ustilago maydis is a plant pathogen that infects specifically Z. mays and has become a popular model organism for researchers to use in order to better understand fundamental cellular mechanisms such as DNA recombination and repair (Holliday, 1964) as well as host-pathogen interactions. The fungus has the ability to reproduce both sexually and asexually depending on the stage of its lifecycle. In order to infect its host plant maize, haploid basidiospores must mate and undergo a dimorphic switch to become infectious. This dimorphic switch is characterized by diploid cells growing into a weblike filamentous form that acts to infect the host after plant surface penetration via the appressoria. This dimorphic switch is observed in other human pathogenic fungi such as Histoplasma capsulatum and Candida albicans (Nadal et al., 2008). A featured characteristic of $U$. maydis infection is the presence of black tumor-like galls that, upon maturation, rupture and release teliospores.

Phosphatidylinositol-4,5-bisphosphate 3-kinases (PI3Ks) are a family of enzymes involved in many important cellular processes such as cell growth, metabolism, proliferation, cell survival, and vesicle trafficking (Engelman et al., 2006). PI3Ks are intracellular signal transducer enzymes that phosphorylate the D3 position hydroxyl groups of the inositol rings of phosphatidylinositol lipids (Katso et al., 2001).The lipid products of PI3K action go on to act as secondary messengers that bind and activate many cellular target proteins involved in a vast array of signaling pathways that play a 
central role in cellular functioning (Katso et al., 2001). The availability of the whole genome sequence of $U$. maydis has revealed that $U$. maydis contains candidate PTEN and PI3K related orthologues (Kämper et al., 2006). It is possible that these genes could play a part of crucial cell growth promoting and proliferation pathways involved in the pathogenicity of the fungus. The goal of this study is to determine if disrupting various aspects of the PI3K/PTEN pathway will interfere with cell viability, mating, pathogenicity, and gall production of $U$. maydis.

\section{MATERIALS AND METHODS}

STRAINS AND GROWTH CONDITIONS: The strains of $U$. maydis used in this study are presented in Table 1 . Strains were grown at $25^{\circ} \mathrm{C}$ in solid or liquid YEPS medium $[1 \%(\mathrm{w} / \mathrm{v})$ yeast extract, $2 \%(\mathrm{w} / \mathrm{v})$ sucrose, and $2 \%(\mathrm{w} / \mathrm{v})$ peptone] (Fisher Scientific, Fair Lawn, NJ), solid YEPS had 2\% (w/v) agar. Strains were grown in liqud, with shaking over night at $260 \mathrm{rpm}$. Mating media was made with solid YEPS and 1\% activated charcoal. Stressing media were made with solid YEPS and either congo red (CR, Fisher, Scientific Company, Fairlawn, JJ, $15 \mu \mathrm{g} / \mathrm{ml}$ ), sodium chloride (1M), or sorbitol (1M) as described in (Cervantes-Chávez et al., 2011). 
Table 1: Origin and genotypes of $U$. maydis strains

\begin{tabular}{lll}
\hline Strains & Genotypes & Reference or source \\
\hline $1 / 2 \mathrm{WT}$ & $\mathrm{a} 1 \mathrm{~b} 1$ & (Gold et al., 1997) \\
2/9 WT & $\mathrm{a} 2 \mathrm{~b} 2$ & (Gold et al., 1997) \\
1/2 PtenOvex & $\mathrm{a} 1 \mathrm{~b} 1 \mathrm{P}_{\text {otef }}-\mathrm{Pten} / \mathrm{cbx}^{\mathrm{R}}$ & This Study \\
2/9 PtenOvex & $\mathrm{a} 2 \mathrm{~b} 2 \mathrm{P}_{\text {otef-Pten }} / \mathrm{cbx}^{\mathrm{R}}$ & This Study \\
1/2 UPTN KO \#3 & $\mathrm{a} 1 \mathrm{~b} 1 \mathrm{Pten} \Delta:: \mathrm{cbx}^{\mathrm{R}}$ & Cau Pham, Univ of Louisville \\
2/9 UPTN KO \#3 & $\mathrm{a} 2 \mathrm{~b} 2 \mathrm{Pten} \Delta:: \mathrm{cbx}^{\mathrm{R}}$ & Cau Pham, Univ of Louisville \\
1/2Pi3KOvex & $\mathrm{a} 1 \mathrm{~b} 1 \mathrm{P}_{\text {otef }}-\mathrm{PI} 3 \mathrm{~K} / \mathrm{cbx}^{\mathrm{R}}$ & This Study \\
2/9Pi3KOvex & $\mathrm{a} 2 \mathrm{~b} 2 \mathrm{P}_{\text {otef-PI3K }} / \mathrm{cbx}^{\mathrm{R}}$ & This Study \\
\hline
\end{tabular}

PRIMER DESIGN AND PCR: All primers were designed using the Primer3 software (http://biotools.umassmed.edu/bioapps/primer3 www.cgi) and based on the genome sequence from JGI (http://genome.jgi.doe.gov/Ustma1/Ustma1.home.html). All primers listed in table 2 were obtained from Eurofins MWG Operon (Huntsville, AL). PCR was run using an Eppendorf Mastercycler (Bio-Rad Laboratories, Hercules, CA), T100 Thermal Cycler (Bio-Rad Laboratories, Hercules, CA), or PTC100 thermal controller (MJ Research Inc., San Fransisco, CA). ExTaq DNA Polymerase (Takara/Clontech laboratories, Inc.) was used for all PCR.

Table 2: List of Primers

\begin{tabular}{ll}
\hline Primer & Sequence(5'-3') \\
\hline PI3KOvexL & ATGGACCGCGCTTTTACTC \\
PI3KOvexR & CCTGAAGTACTGCGCCATATC \\
PtenOtefL & GGATCCATGACGTCCATCGCACGTCGAAT \\
PtenOtefR & GCGGCCGCTTACTGTACCTCTTGTTC \\
UPTN-K1 & TAGGGATAACAGGGTAATCAACAAAATGACGCAACCAC \\
UPTN-K3 & GGGGACAAGTTTTACAAAAAAGCAGGCTAA \\
& GAACGATGTTGCGTGTCAG \\
UPTN-K4 & GGGGACCACTTTGTACAAGAAAGCTGGGTA \\
& CGTTAGACAAAGCGCAATCA \\
UPTN-K2 & GGAAGGTGATCGTGAAGGAA \\
\hline
\end{tabular}




\section{GENETIC MANIPULATION AND VECTOR CONSTRUCTION: PCR}

products were separated by gel electrophoresis through $0.8 \%$ agarose (Agarose LE, USB Corp, Cleveland, $\mathrm{OH}$ ) and extracted and purified using the Zymoclean Gel DNA Recovery Kit (Zymo Research, Irvine, CA). PCR (polymerase chain reaction) products were cloned into pCR2,1 TOPO vector (Invitrogen). Plasmid DNA was purified and DNA samples were sequenced by the Nucleic Acids Core Facility (Center for Genetics and Molecular Medicine, University of Louisville, Louisville, KY). Restriction enzymes were purchased from New England Biolabs, Inc. (Beverllry, MA). Background strains of mating type 1/2 and 2/9 (Gold et al., 1997) used in this study were provided by Cau Pham (Univ. of Louisville). U. maydis protoplasts were produced and transformed with the purified constructs to generate the deletion and / or overexpression strains of PTEN and PI3K using homologous recombination described previously (Brachmann et al., 2004) The PTEN deletion construct was created using an SfiI restriction enzyme-mediated technique (Brachmann et al., 2004). Constructs were either digested by specific restriction endonucleases, or a PCR product was amplified, purified, and used to transform U.maydis protoplasts. Upsteam and downstream fragments of PTEN, each roughly $1 \mathrm{~kb}$ in length, were amplified by PCR. Carboxin and hygromycin resistance cassettes were used as markers and cloned between the up and down flanks in the SfiI sites. The overexpression strains were constructed using primers designed to amplify the entire coding regions of both PTEN (UMAG03760) and PI3K (UMAG00453). The PI3K construct was digested with EcoRl and the vector Otef Cbx-Hyg (a derivative of p123 (Weber et al., 2006)) was cleaved with Stu1. The Otef Cbx-Hyg vector was treated with phosphatase to facilitate the directional insertion of PI3K into the vector and to prevent 
the vector from self-ligating. The PI3K Otef Cbx-Hyg plasmid construct was ligated and transformed into One Shot TOP10 Chemically competent cells (Invitrogen). The negative control contained the vector with no insert to see if the vectors could self-ligate. The PTEN Otef Cbx-Hyg plasmid was derived by removing PTEN cloned in pCR XL-TOPO, by digestion with BamH1 and Not1 and cloning into similarly undigested Otef Cbx-Hyg vector (Weber et al., 2006). Potential PTEN otef-Cbx-Hyg clones were digested with Sspl and used for transformation. Potential transformants were confirmed by PCR amplification screening and DNA sequencing of the plasmids. Deletion strains and the plasmid containing PTEN in pCR2.1 TOPO were provided by Cau Pham (Univ. of Louisville).

CELL VIABILITY ON STRESS MEDIA: Stressing media employed solid YEPS with congo red, $1 \mathrm{M}$ sorbitol, or $1 \mathrm{M} \mathrm{NaCl}$. Cell suspensions were spotted $(10 \mu 1$ of haploid cell strains in exponential growth phase as measured by absorbance at $600 \mathrm{~nm}$ ) using ten-fold serial dilutions with a starting concentration of $10^{7}$ cells/ $\mathrm{ml}$ and decreasing to $10^{4}$ cells / $\mathrm{ml}$ as described in (Cervantes-Chávez et al., 2011). Statistical analysis of results was performed using MetaMorph imaging software (Results not shown) (MDS Analytical Technologies Inc., Mississauga, Ontario, Canada).

MATING ASSAY AND PLANT INFECTION: Exponentially growing $U$. maydis cells having a concentration of roughly $10^{7}$ cells $\mathrm{ml}^{-1}$ were used for plate mating assay (Mayorga and Gold, 1999) and plant infection (Gold et al., 1997) Liquid YEPS media was inoculated with strains and shaken 24 hours to exponential phase of growth ( $\mathrm{A}_{600}$ of 0.5 to 0.8 ), as measured spectrophotometrically. For charcoal plate matting, $10 \mu 1$ volume was spotted for each mating-mixture and photos were taken at 24 and 48 hours 
post plating. Mating efficiency was measured in terms of intensity of 'White Fuzz' for each spot. Average intensity was measured for each spot using MetaMorph imaging software (MDS Analytical Technologies Inc., Mississauga, Ontario, Canada). Plant infection using 8 day old corn seedlings (Bunton Seed Co., Louisville, KY and W. Atlee Burpee \& Co., Warminster, PA) was performed as previously described (Gold et al., 1997). Virulence was rated by a disease index on a scale of 0 to 5 with $0=$ no symptoms, $1=$ chlorosis and $/$ or anthocyanin biosynthesis, $2=$ small leaf galls, $3=$ large leaf galls and $/$ or small stem galls, $4=$ large stem galls, and $5=$ plant death from infection. Ratings were assigned to each plant after 7 days post infection ( +8 days post planting). Two independent infections were performed, averaged, and analyzed.

STATISTICAL ANALYSIS: Statistical analysis of the disease index measure was performed using a Kruskal-Wallis ANOVA with a Dunn's Multiple Comparison Test using the open source R 3.1.1 statistical analysis software available at (http://cran.rproject.org).

\section{RESULTS}

To determine if genetic manipulation of the PTEN (UMAG03760) and PI3K (UMAG00453) genes associated with $U$. maydis cause an observable impact on mating, cell integrity and pathogenicity, strains with deletion and/or over-expression of the genes of interest were constructed in $1 / 2$ and 2/9 U. maydis backgrounds and used for the purpose of comparison in this study. 


\section{MATING EFFICIENCY IN U.MAYDIS MUTANTS:}

PTENOvex and PTENKO mutants: $U$. maydis mating efficiency assay spotted on YEPS medium with activated charcoal were viewed at 24 and 48 hours. Results by measuring 'fuzz' intensity of growth indicate that there was no significant observable difference in mating efficiency of $U$. maydis WT vs $U$. maydis mutant PTEN strains in $1 / 2$ and 2/9 backgrounds. There is no difference between mutant and comparison wild type.

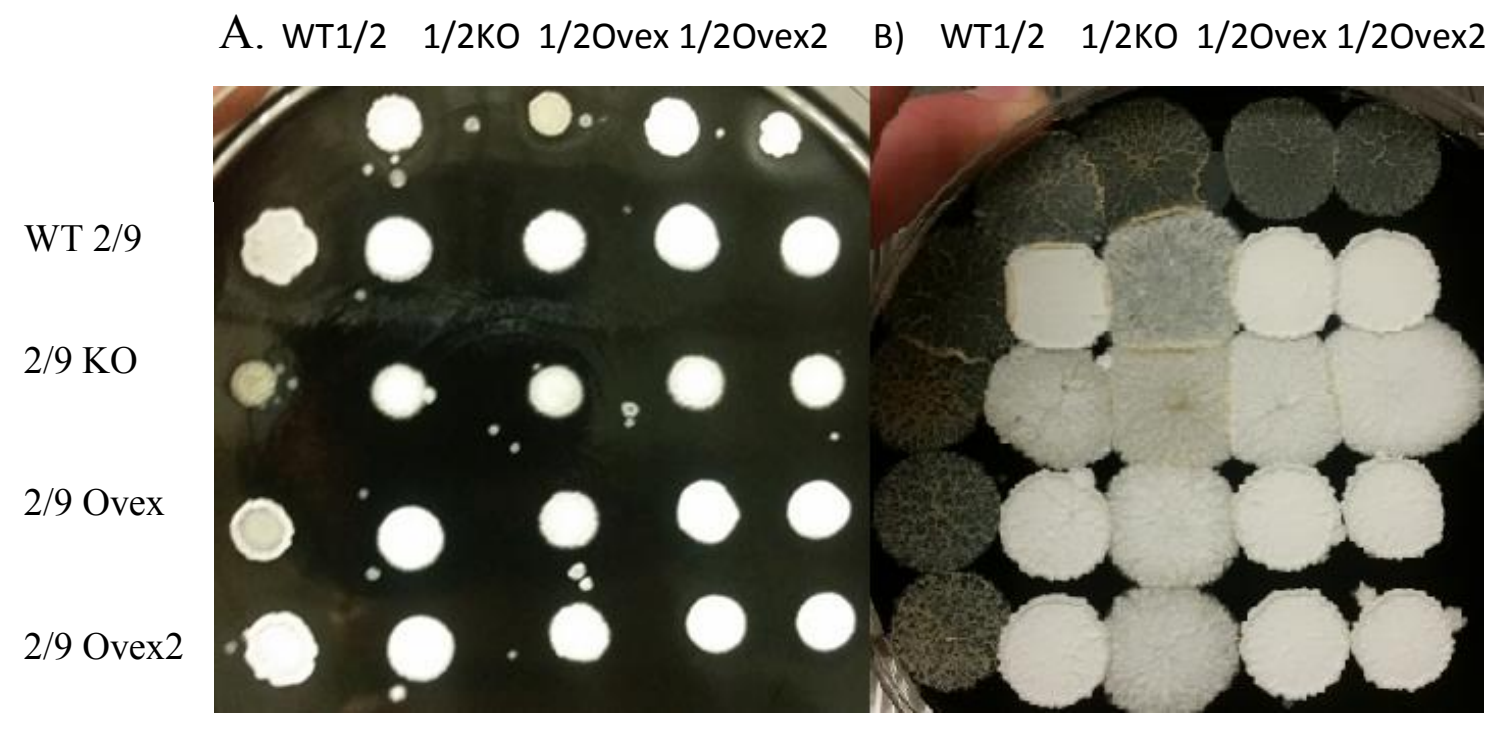

Figure 6: Mating of $U$. maydis PTEN strains YEPS plates supplemented with $1 \%$ activated charcoal. A) Growth after $24 \mathrm{hrs}$. B) Growth after 48hrs.

STRESS VIABILITY IN U.MAYDIS MUTANTS: Wild type, mutant PTEN, and mutant PI3K strains were grown on YEPS supplemented with compounds known to cause various stresses on growth conditions. Strains plated on YEPS containing 1M sorbitol and $1 \mathrm{M} \mathrm{NaCl}$ revealed no observable difference between WT and mutant PI3K and PTEN strains in 1/2 and 2/9 backgrounds. On YEPS plates supplemented with CR, ptenOtef $1 / 2$ strains showed an observable difference, responding better to this stress than WT as seen in Figure 7. 


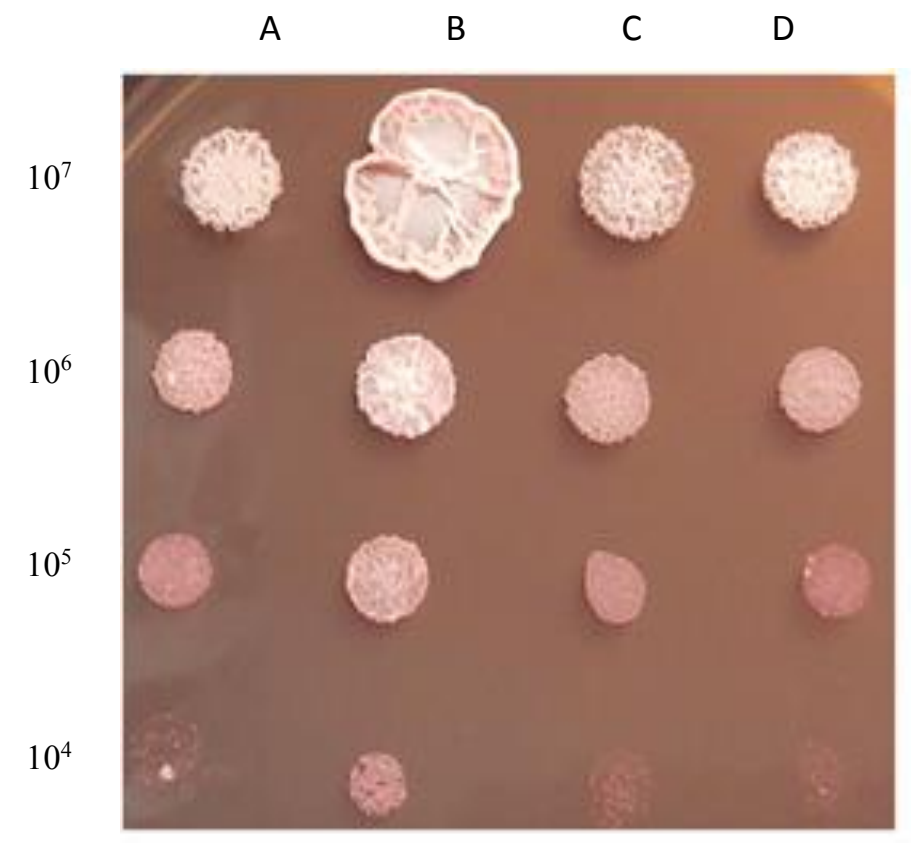

A1 B1

C1

D1

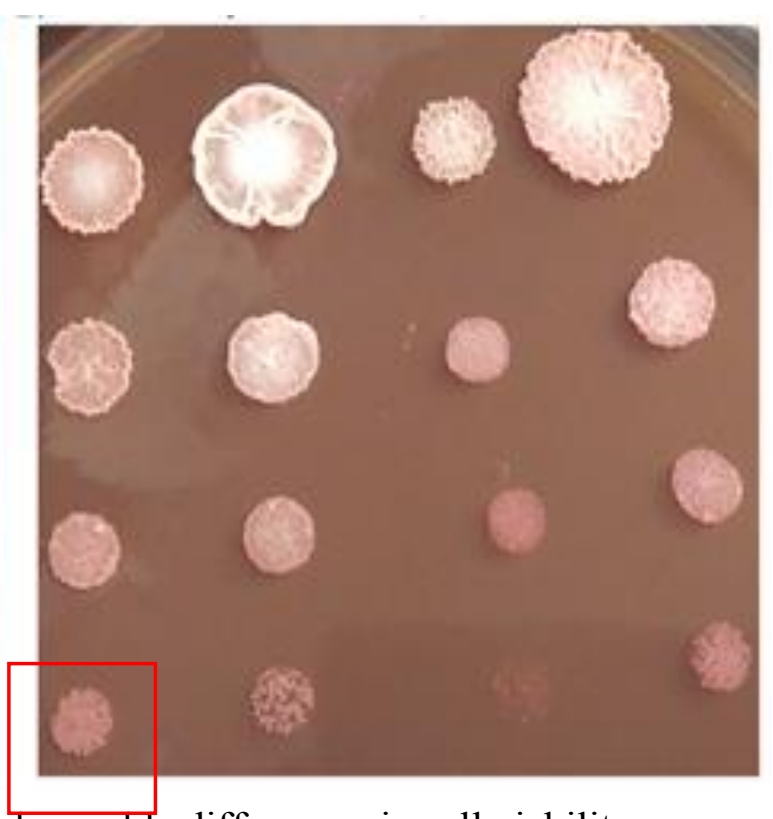

Figure 7: ptenKO and ptenOvex mutants show observable differences in cell viability compared to their wild type progenitor strains while growing on YEPS media supplemented with Congo red. Order: A) WT 1/2. B) WT 2/9. C) ptenKO1/2. D) ptenKO 2/9. A1) ptenOvex1/2. B1) ptenOvex2/9. C1) pi3kOvex 1/2. D1) pi3kOvex2/

\section{PATHOGENICITY IN U.MAYDIS MUTANTS:}

\section{PI3K/PTENOvex and PTENKO mutants: U.maydis PTEN overexpression}

mutants initially showed promising results of a significant difference in pathogenicity but future assays failed to replicate the results of the first infection. Upon examination of infected maize plants 8 days post infection, I found there was no significant difference in pathogenicity when comparing any of the mutant strains to WT infected plants. 


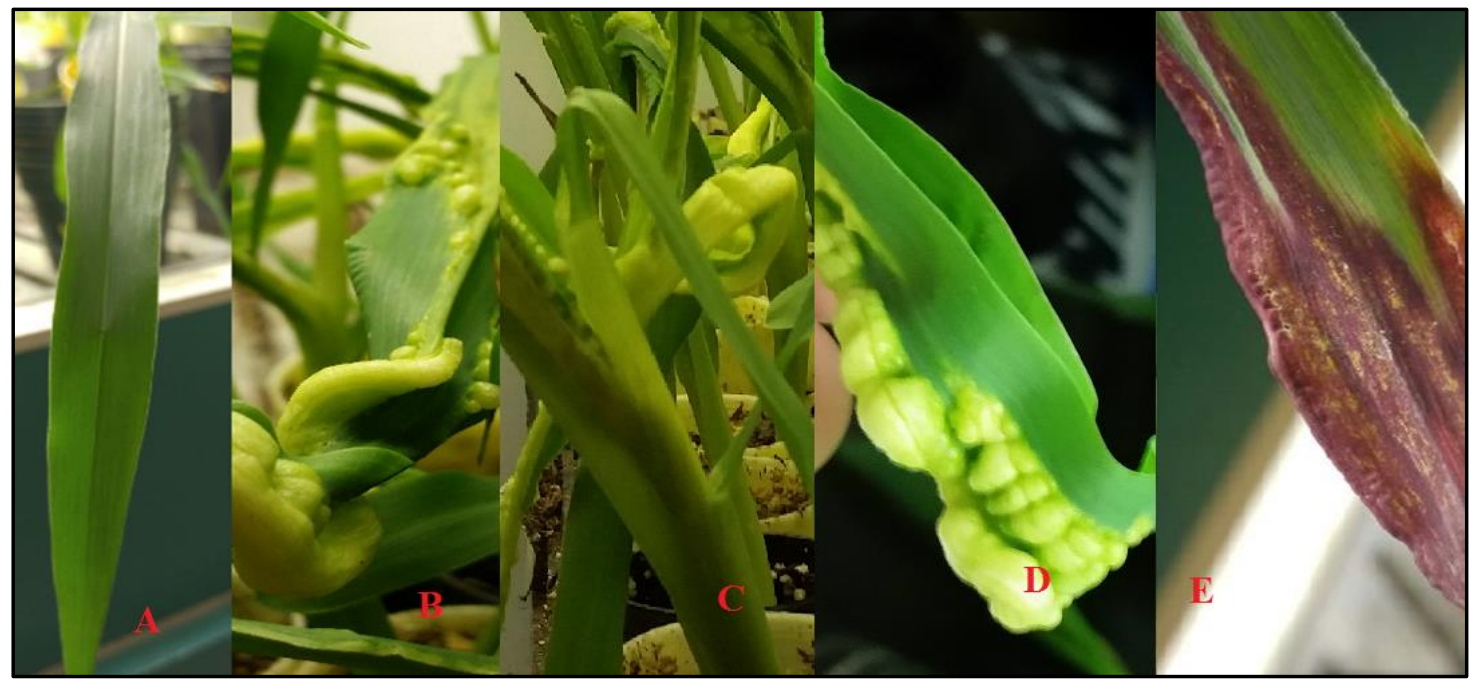

Figure 8: Infections: A) Uninfected B) WT C) PtenOvex D) Pi3kOx E) WT-Chlorosis

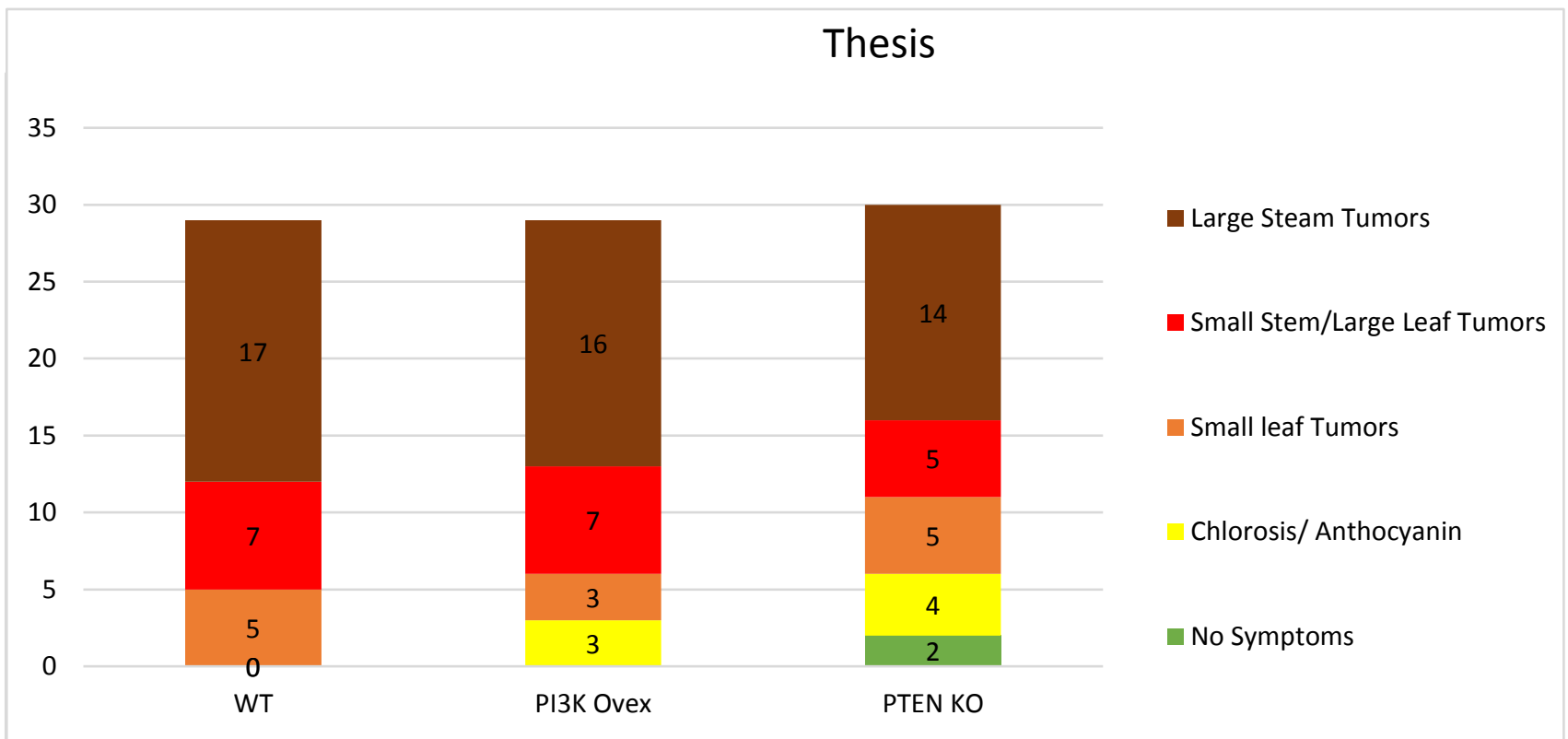

Figure 9: Bar Graph of Infected Scores in Plants July 14 2016. These is no significant difference in these findings $(p<0.05)$.

\section{DISSCUSSION}

PI3Ks are a family of signal transduction kinases consisting of Class I, II, III, and IV PI3Ks. While all of the PI3K enzymes phosphorylate the 3' hydroxyl position of the inositol ring of phosphoinositide, they each generate specific phosphoinositide forms 
(Vanhaesebroeck et al., 2010). Class I and II PI3Ks are only found in metazoans and are responsible for activating certain signals downstream of certain transmembrane receptors, whereas class III PI3Ks are also found in unicellular eukaryotes (Katso et al., 2001). Class I PI3K enzymes are responsible for catalyzing the phosphorylation of the 3' hydroxyl position of the inositol ring associated with the phosphatidylinositol phospholipid, resulting in the formation of phosphatidylinositol $(3,4,5)$-triphosphate $\left(\mathrm{PIP}_{3}\right)$ from phosphatidylinositol $(4,5)$-bisphosphate $\left(\mathrm{PIP}_{2}\right)$. $\mathrm{PIP}_{3}$ acts as a secondary messenger involved in many signaling cascades, including the AKT pathway. Class II and III PI3Ks are differentiated from Class I by differences in structure, function, and regulation. Class II PI3Ks can only synthesize $\mathrm{PIP}_{2}$ and have features such as additional specific $\mathrm{C}$-terminal and $\mathrm{N}$-terminal domains as well as having no regulatory subunits which is atypical compared to the other classes. Class III PI3Ks that have been found in eukaryotes are primarily involved in membrane trafficking. Class III PI3Ks were first found in yeast and described as vacuolar protein sorting (Vsp34). These Vsp34 class III PI3Ks have only been shown to synthesize phosphatidylinositol 3-phosphate molecules from phosphatidylinositol (PI). They are involved in protein and vesicle trafficking as well as playing a primary role in autophagy in yeast and mammals via Vsp34 binding to a protein kinase, Vsp15, and coordinating with Rab5 GTPase to recruit endosomes (Christoforidis et al., 1999).

Our initial plan in research was to select a PI3K homologue in U. maydis of which we chose UMAG00453. Mammalian PI3K research in relation to the PI3K/Akt/mTOR pathway has primarily focused on class I PI3K proteins due to the fact only class I PI3Ks have been observed to have the ability to synthesize PIP. This study was intended to 
investigate the possible effects of genetic manipulation involving PTEN and PI3K orthologues in U. maydis. Upon further inspection into the protein domains of our selected PI3K orthologue utilizing the BLAST bioinformatics tools at the National Center for Biotechnology Information (http://www.ncbi.nlm.nih.gov/), it was revealed that this PI3K related protein actually had conserved regions for Class III PI3K enzymes related to vacuolar protein sorting 34 (Vps34) and no conserved PI3K Class I domains. This oversight in experimental design (i.e. the lack of domains related to Class I PI3Ks) might explain some of the negligible results from our studies involving the PI3K mutants. Vps34 has been shown to be involved in regulation of vesicular trafficking and recruitment of proteins to intracellular membranes involved in the endosomal/lysosomal system (Lindmo and Stenmark, 2006; Odorizzi et al., 2000). Vps34 has also been implicated in nutrient sensing involved with the mTOR pathway in mammalian cells, trimeric G-protein signaling to MAPK in yeast, and autophagy in yeast and higher organisms (Backer, 2008).

Interestingly, studies involving Schizosaccharomyces pombe and S. cerevisiae have found putative PTEN orthologues as well as mammalian PIP3 targets such as PDK1 and PKB/Akt. The similarities of the PTEN yeast orthologues are restricted to the phosphatase PTP catalytic domain similar to the U.maydis orthologue. Deletion of the PTEN orthologue in Sch. pombe yields detectable PIP3 levels which indicates that there are alternative biosynthetic routes in fungi to convert PIP2 to PIP3 and has been suggested to possibly involve the class III PI3K (Vps34) (Cid et al., 2008). It is possible that even though there is no Class I PI3K in $U$. maydis that the class III PI3K may act similar to previous studies using Sch. pombe. 
Mutant PTEN and PI3K strains used in this study had no observable impact on the ability of $U$. maydis to undergo the mating process, indicating that over expressed levels of PTEN and PI3K as well as lack of PTEN play no significant role in $U$. maydis mating. Interestingly there was some indication that PTEN KO and Overexpression strains respond differently than WT to one of the stressful conditions we examined. This may be attributed to the fact that PTEN functions to regulate transmembrane proteins/receptors, thus, overexpression or deletion of PTEN could affect cell wall integrity. This is consistent with the results from the congo red plates as CR is known to reveal cell wall defects (Cervantes-Chávez et al., 2011). Although some disruption has been observed in the mutants when exposed to certain stress promoting conditions, there was no significant difference observed in the ability of the mutants to infect and continue their lifecycle in the host. On the other hand, differences in teliospores production and germination have been observed for the PTEN mutants in preliminary experiments (L. Krishna V, personal communication.)

Although there was no significant difference of infection observed in mutants compared to wild type, plants infected with PTEN overexpression mutants seemed to have a delayed response of infection of 2 to 3 days before rapidly catching up to infection levels of WT, PTEN deletion, and PI3K overexpression strains. This may be the result of the Ovex mutants being unable to continue over-expression of the respective genes inside the plant. Recent studies have shown that the promoter driving expression in these constructs may not be able to constitutively produce proteins past 3 to 4 days in planta ( $\mathrm{J}$. Kämper, personal communication). 


\section{CHAPTER III}

\section{GENERAL CONCLUSION}

The basidiomycete dimorphic fungal pathogen Ustilago maydis has a complex lifecycle that requires infection of a host plant (Klosterman et al., 2007), Zea mays or Zea mexicana. Dimorphic fungi such as $U$. maydis undergo a transition from a yeast-likebudding form to a filamentous form triggered by certain conditions including cues from its host plant low $\mathrm{pH}$, and low nutrient levels. Host infection is characterized by leaf chlorosis, anthocyanin content, and formation of large galls that develop on the stem, leaves, cobs, and flowers of the host plant. Understanding the many different cellular signaling mechanisms involved in this dimorphic switch and infection process is crucial to gain a better understanding of fungal pathogen-host interactions as well as fundamental cellular biology.

The roles of PI3K and PTEN have been well studied in various model organisms but have yet to be fully explored in fungi such as the pathogenic fungus $U$. maydis. The PI3K pathway is known to play a major role in cellular growth and proliferation pathways and the disturbance of this pathway has been implicated to have a major role in many forms of human cancers. This thesis aimed to elucidate the fundamental roles of the target genes UMAG03670 and UMAG00453 and their possible participation in cellular development, stability, and pathogenicity of U. maydis.

Our results have shown that deletion or overexpression of the PTEN related orthologue (UMAG03670) as well as the overexpression of the $P I 3 K$ related orthologue 
(UMAG00453) do not significantly interfere with pathogenicity or mating efficiency in $U$. maydis. Although our results suggest that there is no significant effect on pathogenicity, there is certainly a trend towards significance in the pten KO mutants that warrant further study. These results imply that there are other cellular processes involved with growth and proliferation in $U$. maydis that play a more critical role than the target genes looked at in this study. The overexpression of PTEN in $U$. maydis has an impact on cell viability in at least one stressful condition known to reveal cell wall defects. I believe this could be related to the fact the PTEN protein tyrosine phosphatase domain has been shown to have transmembrane properties that, when overexpressed, could act to strengthen the cell wall by providing additional structural integrity and allow it to respond better to the stressful conditions.

Although our results suggest that PTEN is not essential to the $U$. maydis life-cycle and infection process, the possibility remains that it could be involved in various cellular processes (including teliospores development and germination) and its absence or abundance could affect other cellular functions such as intracellular phosphatidylinositol3,4,5 triphosphate levels described in studies using the model organism Sch. pombe (Cid et al., 2008). Also, the possible roles involving PI3K Class III orthologue Vps34 and interaction in other cellular processes have yet to be examined in $U$. maydis.

\section{FUTURE DIRECTIONS}

The U. maydis PI3K class III Vps34 orthologue could play important roles involved with various cellular processes such as mTOR signaling, trimeric G-protein signaling to MAPK in yeast, and autophagy (Carracedo and Pandolfi, 2008). It would be interesting to explore the possibility that Vps34 plays a role in autophagy induced by 
nutrient limitation as well as the possibility that Vps34 is involved in conversion of PIP2 to PIP3 in U. maydis. Additionally, my hypothesis is that the deletion of the PTEN (UMAG03670) will give rise to observable levels of PIP3 in U. maydis which would indicate an alternate biosynthetic route in the conversion of PIP2 to PIP3. The role of Vps34 in the conversion of PIP2 to PIP3 has been implied in studies using Sch. pombe and a similar role could be observed in U. maydis (Cid et al., 2008). To test this hypothesis the following experiments could be performed:

1) Generation of a PI3K Class III KO construct using primers generated from the left and right flanking sequence regions of UMAG00453.

2) Detecting and measures cellular levels of PIP2 and PIP3 in WT, PTEN KO, and PI3K KO $U$. maydis strains in $1 / 2$ and $2 / 9$ in different stages of $U$. maydis lifecycle.

3) Determining if UMAG00453 is involved in vesicle sorting, autophagy, mTOR signaling, and trimeric G-protein signaling by adapting assays seen in previous studies (Carracedo and Pandolfi, 2008).

4) Testing for growth chamber edge effect impact on plants.

5) Measurement of infection symptoms on a daily basis after infection to determine if mutant strains have a delayed infection response. 


\section{REFERENCES}

Agarwal, C., D.J. Schultz, and M.H. Perlin. 2010. Two phosphodiesterases from Ustilago maydis share structural and biochemical properties with non-fungal phosphodiesterases. Frontiers in microbiology. 1.

Alexopoulos, C.J. 1952. Introductory mycology. Soil Science. 74:481.

Ali, I.U., L.M. Schriml, and M. Dean. 1999. Mutational spectra of PTEN/MMAC1 gene: a tumor suppressor with lipid phosphatase activity. Journal of the National Cancer Institute. 91:1922-1932.

Alves, M.J., I.C. Ferreira, J. Dias, V. Teixeira, A. Martins, and M. Pintado. 2012. A review on antimicrobial activity of mushroom (Basidiomycetes) extracts and isolated compounds. Planta Medica. 78:1707-1718.

Backer, J.M. 2008. The regulation and function of Class III PI3Ks: novel roles for Vps34. Biochemical Journal. 410:1-17.

Bafico, A., and S.A. Aaronson. 2003. Signaling pathways of tyrosine kinase receptors.

Baldauf, S.L., and J.D. Palmer. 1993. Animals and fungi are each other's closest relatives: congruent evidence from multiple proteins. Proceedings of the National Academy of Sciences. 90:11558-11562.

Bardwell, L. 2005. A walk-through of the yeast mating pheromone response pathway. Peptides. 26:339-350.

Berk, A., S. Zipursky, and H. Lodish. 2000. Molecular Cell Biology 4th edition.

Bölker, M. 2001. Ustilago maydis-a valuable model system for the study of fungal dimorphism and virulence. Microbiology. 147:1395-1401.

Bos, J.L., H. Rehmann, and A. Wittinghofer. 2007. GEFs and GAPs: critical elements in the control of small G proteins. Cell. 129:865-877.

Brachmann, A., J. König, C. Julius, and M. Feldbrügge. 2004. A reverse genetic approach for generating gene replacement mutants in Ustilago maydis. Molecular Genetics and Genomics. 272:216-226.

Brachmann, A., J. Schirawski, P. Müller, and R. Kahmann. 2003. An unusual MAP kinase is required for efficient penetration of the plant surface by Ustilago maydis. The EMBO journal. 22:2199-2210.

Brefort, T., G. Doehlemann, A. Mendoza-Mendoza, S. Reissmann, A. Djamei, and R. Kahmann. 2009. Ustilago maydis as a pathogen. Annual review of phytopathology. 47:423-445.

Cantley, L.C., and B.G. Neel. 1999. New insights into tumor suppression: PTEN suppresses tumor formation by restraining the phosphoinositide 3-kinase/AKT pathway. Proceedings of the National Academy of Sciences. 96:4240-4245.

Carracedo, A., and P. Pandolfi. 2008. The PTEN-PI3K pathway: of feedbacks and cross-talks. Oncogene. 27:5527-5541.

Castellano, E., and J. Downward. 2011. RAS interaction with PI3K more than just another effector pathway. Genes \& cancer. 2:261-274.

Cavalier-Smith, T., and E. Chao. 1995. The opalozoan Apusomonas is related to the common ancestor of animals, fungi, and choanoflagellates. Proceedings of the Royal Society of London B: Biological Sciences. 261:1-6. 
Cervantes-Chávez, J.A., S. Ali, and G. Bakkeren. 2011. Response to environmental stresses, cellwall integrity, and virulence are orchestrated through the calcineurin pathway in Ustilago hordei. Molecular Plant-Microbe Interactions. 24:219-232.

Chalhoub, N., and S.J. Baker. 2009. PTEN and the PI3-kinase pathway in cancer. Annual review of pathology. 4:127.

Chen, R.E., and J. Thorner. 2007. Function and regulation in MAPK signaling pathways: lessons learned from the yeast Saccharomyces cerevisiae. Biochimica et Biophysica Acta (BBA)Molecular Cell Research. 1773:1311-1340.

Christoforidis, S., M. Miaczynska, K. Ashman, M. Wilm, L. Zhao, S.-C. Yip, M.D. Waterfield, J.M. Backer, and M. Zerial. 1999. Phosphatidylinositol-3-OH kinases are Rab5 effectors. Nature cell biology. 1:249-252.

Cid, V., I. Rodríguez-Escudero, A. Andrés-Pons, C. Romá-Mateo, A. Gil, J. den Hertog, M. Molina, and R. Pulido. 2008. Assessment of PTEN tumor suppressor activity in nonmammalian models: the year of the yeast. Oncogene. 27:5431-5442.

Dangl, J.L., and J.D. Jones. 2001. Plant pathogens and integrated defence responses to infection. nature. 411:826-833.

de Hoog, G.S., J. Guarro, J. Gené, and M. Figueras. 2000. Atlas of clinical fungi. Centraalbureau voor Schimmelcultures (CBS).

Dean, R., J.A. Van Kan, Z.A. Pretorius, K.E. Hammond-Kosack, A. Di Pietro, P.D. Spanu, J.J. Rudd, M. Dickman, R. Kahmann, and J. Ellis. 2012. The Top 10 fungal pathogens in molecular plant pathology. Molecular plant pathology. 13:414-430.

Engelman, J.A., J. Luo, and L.C. Cantley. 2006. The evolution of phosphatidylinositol 3-kinases as regulators of growth and metabolism. Nature Reviews Genetics. 7:606-619.

Feofilova, E. 2001. The Kingdom Fungi: Heterogeneity of Physiological and Biochemical Properties and Relationships with Plants, Animals, and Prokaryotes (Review). Applied Biochemistry and Microbiology. 37:124-137.

Frech, M., M. Andjelkovic, E. Ingley, K.K. Reddy, J.R. Falck, and B.A. Hemmings. 1997. High affinity binding of inositol phosphates and phosphoinositides to the pleckstrin homology domain of RAC/protein kinase B and their influence on kinase activity. Journal of Biological Chemistry. 272:8474-8481.

Froufe, H.J., R. Abreu, and I.C. Ferreira. 2011. Using molecular docking to investigate the antibreast cancer activity of low molecular weight compounds present on wild mushrooms. SAR and QSAR in Environmental Research. 22:315-328.

Gao, Y., A. Moten, and H.-K. Lin. 2014. Akt: a new activation mechanism. Cell research. 24.

García-Muse, T., G. Steinberg, and J. Pérez-Martín. 2004. Characterization of B-type cyclins in the smut fungus Ustilago maydis: roles in morphogenesis and pathogenicity. Journal of cell science. 117:487-506.

Gold, S.E., S.M. Brogdon, M.E. Mayorga, and J.W. Kronstad. 1997. The Ustilago maydis regulatory subunit of a CAMP-dependent protein kinase is required for gall formation in maize. The Plant Cell. 9:1585-1594.

González-Fernández, R., E. Prats, and J.V. Jorrín-Novo. 2010. Proteomics of plant pathogenic fungi. BioMed Research International. 2010.

Guarro, J., J. Gené, and A.M. Stchigel. 1999. Developments in fungal taxonomy. Clinical microbiology reviews. 12:454-500.

Hawksworth, D.L. 2001. The magnitude of fungal diversity: the 1.5 million species estimate revisited. Mycological research. 105:1422-1432.

Hemmings, B.A., and D.F. Restuccia. 2012. Pi3k-pkb/akt pathway. Cold Spring Harbor perspectives in biology. 4:a011189. 
Holliday, R. 1964. A mechanism for gene conversion in fungi. Genetical Research. 5:282-304.

Horbach, R., A.R. Navarro-Quesada, W. Knogge, and H.B. Deising. 2011. When and how to kill a plant cell: infection strategies of plant pathogenic fungi. Journal of plant physiology. 168:51-62.

Howard, R.J., M.A. Ferrari, D.H. Roach, and N.P. Money. 1991. Penetration of hard substrates by a fungus employing enormous turgor pressures. Proceedings of the National Academy of Sciences. 88:11281-11284.

Hubbard, S.R., and W.T. Miller. 2007. Receptor tyrosine kinases: mechanisms of activation and signaling. Current opinion in cell biology. 19:117-123.

Hutz, J.E. 2010. Genetic analysis of the PI3k/AKT/mTOR signaling pathway. WASHINGTON UNIVERSITY IN ST. LOUIS.

James, T.Y., F. Kauff, C.L. Schoch, P.B. Matheny, V. Hofstetter, C.J. Cox, G. Celio, C. Gueidan, E. Fraker, and J. Miadlikowska. 2006. Reconstructing the early evolution of Fungi using a six-gene phylogeny. Nature. 443:818-822.

Jean, S., and A.A. Kiger. 2014. Classes of phosphoinositide 3-kinases at a glance. Journal of cell science. 127:923-928.

Kaffarnik, F., P. Müller, M. Leibundgut, R. Kahmann, and M. Feldbrügge. 2003. PKA and MAPK phosphorylation of Prf1 allows promoter discrimination in Ustilago maydis. The EMBO journal. 22:5817-5826.

Kahmann, R., and J. Kämper. 2004. Ustilago maydis: how its biology relates to pathogenic development. New Phytologist. 164:31-42.

Kakinuma, N., B.C. Roy, Y. Zhu, Y. Wang, and R. Kiyama. 2008. Kank regulates RhoA-dependent formation of actin stress fibers and cell migration via 14-3-3 in PI3K-Akt signaling. The Journal of cell biology. 181:537-549.

Kämper, J., R. Kahmann, M. Bölker, L.-J. Ma, T. Brefort, B.J. Saville, F. Banuett, J.W. Kronstad, S.E. Gold, and O. Müller et al. 2006. Insights from the genome of the biotrophic fungal plant pathogen Ustilago maydis. Nature. 444:97-101.

Kämper, J., M. Reichmann, T. Romeis, M. Bölker, and R. Kahmann. 1995. Multiallelic recognition: nonself-dependent dimerization of the $\mathrm{bE}$ and bW homeodomain proteins in Ustilago maydis. Cell. 81:73-83.

Katso, R., K. Okkenhaug, K. Ahmadi, S. White, J. Timms, and M.D. Waterfield. 2001. Cellular function of phosphoinositide 3-kinases: implications for development, immunity, homeostasis, and cancer. Annual review of cell and developmental biology. 17:615-675.

Klosterman, S.J., M.H. Perlin, M. Garcia-Pedrajas, S.F. Covert, and S.E. Gold. 2007. Genetics of morphogenesis and pathogenic development of Ustilago maydis. Advances in genetics. 57:1-47.

Kumar, M.N.R. 2000. A review of chitin and chitosan applications. Reactive and functional polymers. 46:1-27.

Legras, J.L., D. Merdinoglu, J. Cornuet, and F. Karst. 2007. Bread, beer and wine: Saccharomyces cerevisiae diversity reflects human history. Molecular ecology. 16:2091-2102.

Lengeler, K.B., R.C. Davidson, C. D'souza, T. Harashima, W.-C. Shen, P. Wang, X. Pan, M. Waugh, and J. Heitman. 2000. Signal transduction cascades regulating fungal development and virulence. Microbiology and Molecular Biology Reviews. 64:746-785.

Leveleki, L., M. Mahlert, B. Sandrock, and M. Bölker. 2004. The PAK family kinase Cla4 is required for budding and morphogenesis in Ustilago maydis. Molecular microbiology. 54:396-406.

Lindmo, K., and H. Stenmark. 2006. Regulation of membrane traffic by phosphoinositide 3kinases. Journal of cell science. 119:605-614. 
Lutzoni, F., F. Kauff, C.J. Cox, D. McLaughlin, G. Celio, B. Dentinger, M. Padamsee, D. Hibbett, T.Y. James, and E. Baloch. 2004. Assembling the fungal tree of life: progress, classification, and evolution of subcellular traits. American journal of botany. 91:1446-1480.

Maehama, T., and J.E. Dixon. 1998. The tumor suppressor, PTEN/MMAC1, dephosphorylates the lipid second messenger, phosphatidylinositol 3, 4, 5-trisphosphate. Journal of Biological Chemistry. 273:13375-13378.

Manning, B.D., and L.C. Cantley. 2007. AKT/PKB signaling: navigating downstream. Cell. 129:1261-1274.

Martínez-Espinoza, A.D., M.a.D. García-Pedrajas, and S.E. Gold. 2002. The Ustilaginales as plant pests and model systems. Fungal genetics and biology. 35:1-20.

Mayorga, M.E., and S.E. Gold. 1999. A MAP kinase encoded by the ubc3 gene of Ustilago maydis is required for filamentous growth and full virulence. Molecular microbiology. 34:485497.

Nadal, M., M.D. García-Pedrajas, and S.E. Gold. 2008. Dimorphism in fungal plant pathogens. FEMS Microbiology Letters. 284:127-134.

Nanba, H., Y. Adachi, and M. Otsuka. 1994. Blood pressure-lowering activity present in the fruit body of Gtifola frondosa. Chemical and Pharmaceutical Bulletin. 36:1000-1006.

New, D.C., and Y.H. Wong. 2007. Molecular mechanisms mediating the G protein-coupled receptor regulation of cell cycle progression. Journal of molecular signaling. 2:1.

O'Brien, H.E., J.L. Parrent, J.A. Jackson, J.-M. Moncalvo, and R. Vilgalys. 2005. Fungal community analysis by large-scale sequencing of environmental samples. Applied and environmental microbiology. 71:5544-5550.

Odorizzi, G., M. Babst, and S.D. Emr. 2000. Phosphoinositide signaling and the regulation of membrane trafficking in yeast. Trends in biochemical sciences. 25:229-235.

Ou, S. 1980. Pathogen variability and host resistance in rice blast disease. Annual review of phytopathology. 18:167-187.

Paez, J., and W.R. Sellers. 2004. PI3K/PTEN/Akt Pathway. In Signal transduction in cancer. Springer. 145-167.

Parfrey, L.W., E. Barbero, E. Lasser, M. Dunthorn, D. Bhattacharya, D.J. Patterson, and L.A. Katz. 2006. Evaluating support for the current classification of eukaryotic diversity. PLoS Genet. 2:e220.

Pataky, J., and K. Snetselaar. 2006. Common smut of corn. The Plant Health Instructor. DOI: 10.1094. PHI-I-2006-0927-01.

Paul, J.A. 2011. Regulation of morphogenesis by ammonium transporters in Ustilgo maydis.

Pham, C.D., Z. Yu, B. Sandrock, M. Bölker, S.E. Gold, and M.H. Perlin. 2009. Ustilago maydis Rho1 and 14-3-3 homologues participate in pathways controlling cell separation and cell polarity. Eukaryotic cell. 8:977-989.

Ruiz-Herrera, J., and A.D. Martínez-Espinoza. 2010. The fungus Ustilago maydis, from the aztec cuisine to the research laboratory. International Microbiology. 1:149-158.

Sánchez-Martínez, C., and J. Pérez-Martín. 2001. Dimorphism in fungal pathogens: Candida albicans and Ustilago maydis - similar inputs, different outputs. Current opinion in microbiology. 4:214-221.

Schirawski, J., B. Heinze, M. Wagenknecht, and R. Kahmann. 2005. Mating type loci of Sporisorium reilianum: novel pattern with three a and multiple b specificities. Eukaryotic cell. 4:1317-1327.

Simpson, A.G., and A.J. Roger. 2004. The real 'kingdoms' of eukaryotes. Current Biology. 14:R693-R696. 
Skamnioti, P., and S.J. Gurr. 2009. Against the grain: safeguarding rice from rice blast disease. Trends in biotechnology. 27:141-150.

Smith, D.G., M.D. Garcia-Pedrajas, W. Hong, Z. Yu, S.E. Gold, and M.H. Perlin. 2004. An ste20 homologue in Ustilago maydis plays a role in mating and pathogenicity. Eukaryotic cell. 3:180-189.

Smith, D.G., M.D. Garcia-Pedrajas, S.E. Gold, and M.H. Perlin. 2003. Isolation and characterization from pathogenic fungi of genes encoding ammonium permeases and their roles in dimorphism. Molecular microbiology. 50:259-275.

Song, G., G. Ouyang, and S. Bao. 2005. The activation of Akt/PKB signaling pathway and cell survival. Journal of cellular and molecular medicine. 9:59-71.

Steinberg, G., and J. Perez-Martin. 2008. Ustilago maydis, a new fungal model system for cell biology. Trends in cell biology. 18:61-67.

Sulis, M.L., and R. Parsons. 2003. PTEN: from pathology to biology. Trends in cell biology. 13:478483.

Takai, Y., T. Sasaki, and T. Matozaki. 2001. Small GTP-binding proteins. Physiological reviews. 81:153-208.

Taylor, T.N., and J.M. Osborn. 1996. The importance of fungi in shaping the paleoecosystem. Review of Palaeobotany and Palynology. 90:249-262.

Tudzynski, P., and A. Sharon. 2003. 9-Fungal Pathogenicity Genes. Applied mycology and biotechnology. 3:187-212.

Vanhaesebroeck, B., and D.R. Alessi. 2000. The PI3K-PDK1 connection: more than just a road to PKB. Biochemical Journal. 346:561-576.

Vanhaesebroeck, B., J. Guillermet-Guibert, M. Graupera, and B. Bilanges. 2010. The emerging mechanisms of isoform-specific PI3K signalling. Nature reviews Molecular cell biology. 11:329-341.

Vara, J.Á.F., E. Casado, J. de Castro, P. Cejas, C. Belda-Iniesta, and M. González-Barón. 2004. PI3K/Akt signalling pathway and cancer. Cancer treatment reviews. 30:193-204.

Weber, I., D. Aßmann, E. Thines, and G. Steinberg. 2006. Polar localizing class V myosin chitin synthases are essential during early plant infection in the plant pathogenic fungus Ustilago maydis. The Plant Cell. 18:225-242.

Wennerberg, K., K.L. Rossman, and C.J. Der. 2005. The Ras superfamily at a glance. J Cell Sci. 118:843-846.

Whittaker, R.H. 1969. New concepts of kingdoms of organisms. Science. 163:150-160.

Yadav, S.S., J. Li, H.J. Lavery, K.K. Yadav, and A.K. Tewari. 2015. Next-generation sequencing technology in prostate cancer diagnosis, prognosis, and personalized treatment. In Urologic Oncology: Seminars and Original Investigations. Vol. 33. Elsevier. 267. e261267. e213. 


\section{APPENDIX}

Table A: Infection scores of plants Trial 1

\begin{tabular}{|l|r|r|r|r|r|r|}
\hline Treatmen WT & PI3K OV & PTEN KO & Mock & Un-Inf \\
\hline 8th day & 3.51 & 3.36 & 2.77 & 0 & 0 \\
\hline Plants & 31 & 30 & 27 & 17 & 20 \\
\hline
\end{tabular}

Table B: Infection scores of plants Trial 2

\begin{tabular}{|l|r|r|r|r|r|r|r|}
\hline Treatmen WT & PI3K-OV & PTEN-KO & PTEN-OV & Mock & \multicolumn{2}{|c|}{ Un-Inf } \\
\hline 8th day & 2.1 & 2.6 & 1.36 & 2.33 & 0 & 0 \\
\hline Plants & 30 & 30 & 30 & 30 & 15 & 17 \\
\hline
\end{tabular}

Table C: Infection scores of plants Trial 3

\begin{tabular}{|l|r|r|r|r|r|r|}
\hline \multicolumn{2}{|c|}{ Treatment groups } & & & & \\
\hline & $1 / 2 \& 2 / 9$ & PTEN OV & PTEN KO & Mock & Un-Inf \\
\hline 8th day & 3.36 & 2.56 & 2 & 0 & 0 \\
\hline Plants & 33 & 32 & 34 & 21 & \\
\hline
\end{tabular}




\title{
CURRICULUM VITA
}

NAME: Nathaniel Edward Dalton

ADDRESS: Department of Biology 139, Life Sciences Building 406 Stilz Ave, Apt 2 Belknap Campus Louisville, Kentucky

University of Louisville 812-946-5020

Louisville, Kentucky 40292 natdalto@gmail.com

EDUCATION

\& TRAINING:

\author{
B.S., Science \\ Informatics - Biology Cognate \\ Indiana University Southeast
}

2009-2013

M.S., Biology

University of Louisville

Kentucky, United States

December 2016

\section{GRADUATE COURSE WORK:}

Adv. Intermediate Metabolism

Adv. Biostatistics

Independent Research - Fungal Transformation

Adv. Medical Plant Biochemistry

Adv. Gene Structure and Function

Adv. Developmental Biology Independent Research - PTEN Signaling 